\title{
A Fusion Reactor Design with a Liquid First Wall and Divertor
}

R. E. Nygren, T. D. Rognlien, M. E. Rensink, S. S. Smolentsev, M. E. Youssef, M. Z. Sawan, B. J. Merrill, C. Eberle, P. J. Fogarty, B. E. Nelson, D. K. Sze, R. Majeski

November 14, 2003

Fusion Engineering and Design 
This document was prepared as an account of work sponsored by an agency of the United States Government. Neither the United States Government nor the University of California nor any of their employees, makes any warranty, express or implied, or assumes any legal liability or responsibility for the accuracy, completeness, or usefulness of any information, apparatus, product, or process disclosed, or represents that its use would not infringe privately owned rights. Reference herein to any specific commercial product, process, or service by trade name, trademark, manufacturer, or otherwise, does not necessarily constitute or imply its endorsement, recommendation, or favoring by the United States Government or the University of California. The views and opinions of authors expressed herein do not necessarily state or reflect those of the United States Government or the University of California, and shall not be used for advertising or product endorsement purposes. 
UCRL-JRNL-200954

\title{
A Fusion Reactor Design with a Liquid First Wall and Divertor
}

\author{
R.E. Nygren, Sandia National Laboratories \\ T.D. Rognlien and M.E. Rensink, Lawrence Livermore National Laboratory \\ S.S. Smolentsev and M.E. Youssef, University of California, Los Angeles \\ M.Z. Sawan, University of Wisconsin \\ B.J. Merrill, Idaho National Energy and Environmental Laboratory \\ C. Eberle, P.J. Fogarty and B.E. Nelson, Oak Ridge National Laboratory \\ D.K. Sze, University of California, San Diego \\ R. Majeski, Princeton Plasma Physics Laboratory
}

\begin{abstract}
Within the magnetic fusion energy program in the US, a program called APEX is investigating the use of free flowing liquid surfaces to form the inner surface of the chamber around the plasma. As part of this work, the APEX Team has investigated several possible design implementations and developed a specific engineering concept for a fusion reactor with liquid walls. Our approach has been to utilize an already established design for a future fusion reactor, the ARIES-RS, for the basic chamber geometry and magnetic configuration and to replace the chamber technology in this design with liquid wall technology for a first wall and divertor and a blanket with adequate tritium breeding. This paper gives an overview of one design with a molten salt (a mixture of lithium, beryllium and sodium fluorides) forming the liquid surfaces and a ferritic steel for the structural material of the blanket. The design point is a reactor with $3840 \mathrm{MW}$ of fusion power of which $767 \mathrm{MW}$ is in the form of energetic particles (alpha power) and 3073MW is in the form of neutrons. The alpha plus auxiliary power total 909MW of which $430 \mathrm{MW}$ is radiated from the core mostly onto the first wall and the balance flows into the edge plasma and is distributed between the first wall and the divertor. In pursuing the application of liquid surfaces in APEX, the team has developed analytical tools that are significant achievements themselves and also pursued experiments on flowing liquids. This work is covered elsewhere, but the paper will also note several such areas to indicate the supporting science behind the design presented. Significant new work in modeling the plasma edge to understand the interaction of the plasma with the liquid walls is one example. Another is the incorporation of magneto-hydrodynamic (MHD) effects in fluid modeling and heat transfer.
\end{abstract}

\section{Introduction}

This paper presents a design with flowing liquid walls facing the plasma that is one possible embodiment of the chamber for a magnetic fusion reactor. The effort is a product of the Advanced Power Extraction (APEX) study, a part of the Enabling Technology Program in the US Magnetic Fusion Energy Science Program. APEX is exploring innovative concepts for fusion chamber technology that could dramatically enhance fusion as an attractive and competitive source of energy.[1] Work on liquid surface plasma facing components and related plasma surface interactions, some, of which is described later, is being performed in the Advanced Limiter-Divertor Plasma Facing Systems (ALPS) Program.[2] 
The main focus of APEX has been on how we might use flowing liquids as the inner surface of the vacuum chamber that directly faces the plasma. The attraction of this idea is that, while removing the surface heat load, this liquid surface is continuously renewed and is immune to both the radiation damage and thermal stresses that would affect and limit the performance of a solid chamber wall. Both liquid metals and molten salts have been investigated. APEX has also included studies of systems with solid walls and a paper on this work is also presented in this journal. ${ }^{1}$

In this section, we present background information about APEX and the approach being taken in developing designs for chamber technology. The next section gives a general description of chamber technology and some of the history of our design development and includes some examples of innovative ideas developed for the designs. Subsequent sections present a specific chamber design that utilizes as molten salt (Flinabe) as the working liquid in the chamber and an advanced ferritic steel as the structural material and these section include descriptions on materials, neutronics, tritium processing and safety. The R\&D issues associated with this design are described in a separate section near the end of the paper.

Since our focus is on chamber technology, we do not develop descriptions of the magnets, balance of plant, reactor hall, etc. These elements, along with the physics and plasma technologies, e.g., fueling, that would appear in a complete reactor design are not covered here.

\section{Chamber Technology}

Chamber technology refers to the components in a fusion reactor that interact directly with the plasma, remove the heat, breed tritium fuel and protect the plasma boundary as well as other components like the magnets. The main parts are the first wall, divertor, blanket and shield, and our design development includes the primary heat transfer loop and the tritium recovery system.

A central theme in APEX is to identify radically different solutions in chamber technology that can lead to fusion reactors with smaller volume for a given power (higher power density) and with simple and robust components that are likely to produce high availability in a fusion reactor. When one looks toward the future and what is likely to govern decisions about the economics of fusion energy, the conclusion that power density and availability are dominating factors is inescapable. And chamber technology is the critical link.

The general mission of APEX and an explanation of the considerations of chamber technology and high power density may be found in a paper by the APEX Team Leader, Prof. Mohamed Abdou, and the APEX Team, and in presentations on the APEX website.[1] While ideas for fusion reactors utilizing liquid metals and even liquids with free surfaces facing the plasma in local areas of high heat flux have been presented in the past[3-21], the work in APEX is novel for two reasons. First, new ideas have indeed been developed. Second, the work to investigate and understand the underlying science and engineering needed to advance these concepts goes into a depth that significantly

\footnotetext{
${ }^{1}$ See article by C.P.C. Wong et al. in this journal
} 
exceeds previous work. More information about the economics of fusion may be found in articles by Dr. John Sheffield.[22,23]

\section{Our Approach}

Our intent in this paper is to show the reader a design for a fusion reactor with a liquid wall next to the plasma and to present that design from several viewpoints.

First, the design is a visual embodiment of the technological solutions being developed in APEX and represents one possible vision of a future fusion power plant.. A design study forces the integration of many competing requirements into a self-consistent whole. For example, heat removal is very challenging. Increasing the fusion power density means higher heat loads on the components, but increasing the rate of coolant flow also increases the (parasitic) power needed for pumping. Second, we have undertaken several designs and have investigated lithium, tin, tin-lithium and two molten salts (Flibe and Flinabe) as coolants. The paper will be also present highlights from this other design work in addition to the Flinabe design that is presented in some detail.

Third, the design studies draw upon other parts of APEX in which tools are being developed to understand and predict such features as fluid flow and the interaction of the plasma edge with flowing liquids. In these areas, our understanding is sometimes incomplete, but the APEX Team is making significant advances in science and engineering sciences. These advances are also important in their own right and some are noted in this and other papers in this journal issue.

A final viewpoint regarding the design work in APEX is a perspective on chamber technology. The path toward realizing fusion as an energy source depends critically on the development of chamber technology as the means for the eventual deployment of fusion. Progress in chamber technology comes from various disciplines such as fluid mechanics, neutronics, heat transfer and materials science that are wholly outside of plasma physics. Moreover, important goals that directly affect the physics missions of major fusion confinement experiments have both drawn from chamber technology (such as heat removal and wall conditioning systems) and, of more importance here, been driven by developments and conclusions from work in chamber technology. (Examples include the goal of steady state rather than pulsed operation, the need for mitigation of plasma disruptions, the need for RF injection systems because of the problematic shielding requirements for neutral beam ports, and many basic aspects of damage to materials and confirmation that extraction of tritium from solids as well as liquids was possible). The point here is that chamber technology is and has been integrally involved in the quest of managing plasmas, and has sometimes pointed the way. 


\section{Goals for High Power Density and Power Handling}

Chamber technology serves two of the three fundamental functions of fusion energy systems. The first is confining the plasma itself. The second and third are (1) breeding of sufficient tritium to assure that the plasma is self-sustained and that fusion is a "renewable" energy source, and (2) extracting power in a practical, reliable, safe, and economical fusion energy system. The economics pushes fusion toward high power density (fusion power divided by the volume of the plasma) and high-temperature coolants, and these set the overall requirements for tritium breeding and heat removal.[1] In quick summary, our design task address these two system functions in the following way. Neutronic analyses show adequate tritium breeding. Modeling of the plasma edge defines the heat loads, and thermal-hydraulic analyses show that the heat removal is adequate. Evaluation of thermal transport shows an operating point with reasonable thermal efficiency. Evaluation of safety indicates manageable approaches to the issues. A separate paper on safety is presented in this journal. ${ }^{2}$

In our chamber design, we utilize the configuration from an existing design study for a 2170MW D/T fusion power plant called ARIES-RS[24,25], and adapt this for a liquid surface first wall and divertor and a liquid blanket. It has 16 toroidal field coils that surround the plasma chamber. The plasma has a major radius of $5.5 \mathrm{~m}$, an aspect ratio of 4 , a current of $11 \mathrm{MA}$ and a density of $2 \times 10^{20} \mathrm{~m}^{-3}$. For our design, retained the basic magnetic configuration and increased the power density by using a higher fusion power of 3840MW to define the heat loads for the first wall and divertor.

\section{Power Flow}

Where does this power go? About $20 \%$ of the fusion power is in the form of $3.7 \mathrm{MeV}$ helium ions that interact in the plasma and $80 \%$ is $14.1 \mathrm{MeV}$ neutrons that penetrate the chamber wall. The alpha power (helium ions) plus the auxiliary power added to heat the plasma are distributed in the plasma and must be transferred to the chamber wall either as radiation (line or bremsstrahlung) or by direct collisions of particles with the wall. Some fraction of these colliding particles are energetic neutrals produced by charge-exchange processes, but most are ions and electrons at the edge of the plasma. These follow magnetic field lines that intersect two thin toroidal stripes on a component called the divertor. This transfer of energy has to be achieved without overheating and excessively eroding the plasma facing materials and without releasing impurities from the walls that would degrade the thermonuclear burn process. The helium produced in the fusion process has to be removed from the plasma to prevent dilution of the $\mathrm{D} / \mathrm{T}$ ions.

A prerequisite for designing the heat removal systems of the first wall and divertor in high power density devices is a plasma regime in which a large fraction of the alpha power can be converted into radiation in the core and edge plasmas so that the resulting heat load from the charged particles striking the divertor is manageable. While this goal of a high radiative fraction mitigates the peak heat loads, large radiative cooling also tends to decrease the thermal isolation and stability of the core plasma. Developing solutions for plasmas that are stable with this large cooling is a concern, and some recent and important progress in this area will be noted.

\footnotetext{
${ }^{2}$ See article by B. Merrill et al. in this journal
} 
In the jargon of fusion we refer to the radiation coming from the core plasma as core radiation. We also refer to the edge plasma and edge radiation. As noted above, at the plasma edge there are magnetic field lines that intersect the wall. We refer to the surface (boundary) that separates the core with closed magnetic field lines from this outer region as the separatrix, and we call the outer region of plasma the "scrape-off layer" because it is scraped off from the main plasma by being diverted onto the chamber wall, more specifically, onto the divertor.

\section{Power Loads on the First Wall and Divertor}

In our chamber design, the fusion power is $3840 \mathrm{MW}$, the alpha power is $767 \mathrm{MW}$, and $142 \mathrm{MW}$ of auxiliary power are supplied to the plasma to drive currents in the plasma for controlling the distribution of its density and temperature. So a total power of 909MW will be transmitted as surface heat loads to the first wall and divertor. Table 1 gives average heat loads for the design and information on the power balance.

A basic design criterion for the parts of our heat removal systems that face the plasma is that the component should not contaminate the plasma by excess vaporization of material or by ejecting material into the plasma. Solid heat sinks, for example carbon armor on a copper substrate or tungsten, require active cooling to keep the temperature within a range that can preserve the structural integrity. Also, the large temperature gradient between the heated surface and the coolant typically produces significant stresses. For liquid surfaces, the main concerns are excessive evaporation and splashing.

Another basic factor in handling the high surface heat loads is that the high coolant flow rates $(10 \mathrm{~m} / \mathrm{s})$ needed result in a large throughput but small rise in the bulk temperature. This is the least convenient form to remove heat for a power conversion cycle but is accommodated in the design to be described by recirculating part of the first wall flow.

\section{Chamber Configuration}

The three principal features of the fusion chamber are (1) the first wall and divertor, (2) the blanket and (3) the shield (see Fig. 1). The first wall and divertor are directly exposed to the plasma and receive heat converted from the alpha power and auxiliary heating, as noted above. Tritium $\left(\mathrm{H}^{3}\right.$ or $\left.\mathrm{T}\right)$ fuel for the reactor is bred from lithium (Li) contained in the blanket. ${ }^{3}$ The shield protects components such as the magnets from neutron damage. The temperatures and mix of the fluid streams from the first wall, divertor and blanket must be designed for efficient energy conversion. Since high exit temperatures in these coolant streams are generally desirable for power conversion, there is typically a trade-off between the coolant temperatures that can be achieved, the heat loads that can be handled, and the temperature limits of the materials. Designing a solid first wall is challenging primarily because of (1) the thermal stresses that arise in the coolant channels and the radiation damage to this structure and (2) the requirements for remote maintenance associated with the potential threat of leaks from these coolant channels. With a liquid chamber wall, these concerns are eliminated. The issue of radiation damage to structure in the blanket remains, but without the complication of the high surface heat load.

\footnotetext{
${ }^{3}$ The dominant reaction is $\mathrm{Li}^{6}+$ neutron $\square \mathrm{T}+\mathrm{He},+4.78 \mathrm{MeV}$. There is also an endothermic reaction, $\mathrm{Li}^{7}+$ neutron $\square \mathrm{T}+\mathrm{He}+$ neutron, $-2.47 \mathrm{MeV}$.
} 
In our preliminary evaluations of a first wall (FW) and blanket in the APEX design activity, a concept with separated streams of flowing liquid for the FW and blanket initially proposed by Neil Morley of UCLA was deemed the most promising. The first wall is a 2-cm thick "skin" of flowing liquid that surrounds the plasma. Behind the first wall is a blanket of a slower flowing liquid, such as the molten salt Flibe (a combination of lithium and beryllium fluorides, $\mathrm{LiF}-\mathrm{BeF}_{2}$ ) or the liquid metal mixture, $\mathrm{Pb}-\mathrm{Li}$. In the simplest implementation of this concept, the first wall stream also becomes the divertor stream at the bottom of the chamber.

\section{Working Fluids}

Our mechanical design has proceeded through several design concepts. Each concept evaluated has included detailed CAD renderings and several innovative features. Before describing our current design, a brief history of the evolution of this design activity is given here along with a few of the innovative ideas that have come from this work.

Fig. 2 shows the development path of our liquid surface chamber designs and some of our preliminary conclusions. In 1999 and early 2000, we studied a design with the molten salt Flibe as the working liquid, and in 2000 and 2001 with $\mathrm{Li}$ and with Sn-Li. In each case, the same fluid serves as the first wall and as the tritium-breeding medium in the blanket. The Flibe and Li designs had problems with limited windows for operating temperature. Excessive surface temperature (vaporization of F) limited the Flibe design and poor thermal efficiency limited the Li design. The limit in each case was the allowable impurity generation from the wall and this in turn set the restriction in the surface temperature of the fluid.[26] The Li design also had the interesting feature that the brehmsstralung radiation, greater in this design because of a plasma regime with very low recycling and high edge temperature, penetrated into the $\mathrm{Li}$, and this penetration slightly reduced the surface temperature compared to an equivalent, purely-surface heat load. Section 7.4 describes this further.

Each of the designs included a thick liquid blanket with the same working fluid as the first wall. The blanket must contain sufficient Li so that the tritium bred from the Li can fuel the reactor. Also the thick blanket reduces the activation and radiation damage in the structure behind the blanket. The tritium breeding and the neutronic response of the materials behind the blanket are part of the design evaluations and these depend on the blanket material. For example, Li moderates both high-energy and low-energy neutrons well due to inelastic scattering in Li-7 and absorption in Li-6. Flinabe is effective in attenuating high-energy neutrons due to inelastic scattering in $F$ and $(n, 2 n)$ reactions in Be. Section 7 (Tritium Breeding, Nuclear Heating and Shielding) contains references to work on the earlier designs.

In 2000 and 2001 we began evaluating designs with Sn as the first wall stream to be separated from a $\mathrm{Pb}-\mathrm{Li}$ blanket. The analysis of plasma surface interactions gave a fairly good operating temperature range with the surface temperature limit of Sn being 810$840^{\circ} \mathrm{C}$ for the $\mathrm{FW}$ and $1630^{\circ} \mathrm{C}\left(1480^{\circ} \mathrm{C}\right.$ for $\left.\mathrm{Ga}\right)$ for the divertor. However, predictions of the flows for the liquid metal systems were not available due to the difficulty of modeling the magneto-hydrodynamic (MHD) effects that dominate the fluid flow and thus the heat transfer for liquid metal systems in a magnetic fusion reactor. The jet flow from nozzles and flow across magnetic field lines in the divertor are beyond the current state-of-the-art 
in this regard. Fluid flow calculations for $\mathrm{Li}$ (and $\mathrm{Sn}$ ), with simple correlations for the MHD forces and the assumption of an insulating wall, did show that fast thin layers ( $20 \mathrm{~mm}$-thick flow streams launched at $10 \mathrm{~m} / \mathrm{s}$ ) would flow down and adhere to a concave substrate.

Liquid metals are good heat transfer agents because of their high thermal conductivities and low vapor pressures, although Li is somewhat higher in this latter regard. However, one effect of a strong magnetic field is to suppress turbulence. While the contribution of turbulence to heat transfer in low Prandtl number fluids is less important than in coolants such as water, oil or molten salts, the enhancement would nevertheless be helpful in reducing the surface temperature in a liquid metal first wall. An interesting idea with a good scientific basis is the possibility of "2-D" turbulent structures (with the axis of the vorticity parallel to the magnetic field) that might enhance heat transfer in MHDcontrolled liquid metal flows. Some work was done in this area as part of collaborations at UCLA. MHD-controlled free surface liquid metal flows has been an active area of investigation through both modeling and experimental work in APEX and the subject of another article in this journal. ${ }^{4}$ The safety aspects of a chamber with liquid metal walls have also been assessed in APEX.[27]

In FY2002 we began evaluating a design with the molten salt Flinabe as the working fluid. Flinabe is a mixture of lithium, beryllium and sodium fluorides and has similarities to Flibe but also a lower melting point. The melting point is not well known and is the subject of experiments at Idaho National Engineering and Environmental Laboratory. This lower melting point extends the window of operating temperature enough that a workable design appears possible. We began this design with some skepticism since molten salts generally have poor thermal conductivity and good thermal conductivity would seem to be an a priori requirement for any first wall and divertor material. In this regard, our APEX/ARIES design with Flinabe, presented later, is a startling and pleasing result.

\section{Some Innovative Ideas}

In utilizing a Sn-Li mixture, we hoped that the lower activity of the $\mathrm{Li}$ in the $\mathrm{Sn}-\mathrm{Li}$ mixture and lower evaporation rate would raise the allowable surface temperature of the first wall for operation. The increase was a significant, from $380^{\circ} \mathrm{C}$ for $\mathrm{Li}$ to $590^{\circ} \mathrm{C}$ for $0.8 \mathrm{Sn}-0.2 \mathrm{Li}[28]$, but segregation of Li to the surface (driven by a reduction in the surface tension) was also identified as an issue.[29] This segregation presents the intriguing possibility that $\mathrm{Sn}$ with $\mathrm{Li}$ as a minority constituent could have a surface comprised mostly of Li, which would then be preferentially sputtered into the plasma more than $\mathrm{Sn}$ and is a fairly benign impurity. We remain intrigued with this idea; however, we put its implementation into a design on hold because (a) the prediction of liquid metal flows is a challenging problem noted subsequently and (b) the surface chemistry is a bit complicated for predictive modeling of interactions with the edge plasma. A Li-rich surface would also trap hydrogen until it became saturated, but the retention of both the hydrogen and the Li on the surface is a balance between their depletion and supply. The depletion from sputtering and evaporation depend respectively on the flux and energy of

4 See N. Morley et al. "Modeling for liquid metal free surface MHD flow for fusion liquid walls" in this journal; see also, N. B. Morley, S.

Smolentsev and D. Gao, Modeling infinite/axisymmetric liquid metal magnetohydrodynamic free surface flows, FED 63-64 (2002) p343-351 
the deuterium (D) and tritium (T) neutrals coming to the surface and on the temperature of the Sn-Li. The supply of Li from segregation depends on the temperature of the Sn-Li and how much of the evaporated and sputtered material is redeposited. Readers are referred to Ref. 29 for more information.

One of our goals in the APEX design activity has been to minimize the amount of solid structure that is directly exposed to the plasma. Some examples of needed solid structures are flow deflectors that create penetrations for diagnostics and for plasma heating and the nozzles that inject the liquid. Some early work ${ }^{5}$ on the flow of nonconducting fluids around penetrations indicated the potential problems of splashing and flow thickening of the stream adjacent to the flow deflector (penetration wall) could be mitigated by modifying the back wall (underneath the free surface). The challenging calculations were done with a 3-D time-dependent Navier Stokes computational fluid dynamics simulation. Figure 3 shows an example of the flow pattern.

To initiate the first wall flow, authors Nelson and Fogarty invented a system of "self shielding" nozzles. In their clever scheme (Fig. 4), the flows overlap in a way that prevents any line of sight from the plasma to the solid surface of a nozzle. A plastic model of a section of nested nozzles was produced using rapid-prototyping techniques.

Another of their innovations was a flexible "bag" of woven SiC (Fig. 5), rather than a solid partition, to guide Sn-Li in the blanket and separate this from the flowing Li or Sn$\mathrm{Li}$ in the first wall. Semi-permeable, woven "bags" would extend the full height of the machine, and would be relatively narrow in the poloidal direction and deep in the toroidal direction. The bags could easily be deep enough to provide sufficient protection to the back structure to make it a lifetime component. The first wall stream would flow on the faces of the bags toward the plasma, while the bulk flow would enter pipes at the bottom of the bags and exit out the top of the bags. The primary structural load on the bags would be limited to the head pressure of the liquid that is chosen and some small piping losses, but would be on the order of $0.3 \mathrm{MPa}$. Another interesting benefit of the bag concept is that, if we assume that the back plate is separately cooled and we are allowed to "freeze" some liquid as a thermal insulating barrier at the interface to the back plate, then the back plate can be made from ferritic steel (or austenitic, like 304L) and operate within its temperature limits while the main flow of liquid can operate at a much higher temperature. Freezing some material at the boundary of a molten pool is often used as a means of protecting crucibles. The bags would be constructed of a very fine weave of wire or fiber. The material could be anything that is compatible with the fluid ( $\mathrm{SiC}$, graphite, $\mathrm{W}, \mathrm{Ta}, \mathrm{V}$, etc.). A high temperature material is preferred, however, to provide protection against transient, localized loss of flow on the surface and better resistance to creep. Embrittlement of the bag fibers may not be a concern, since very small diameter fibers can remain in the elastic range and still provide a very flexible structure.

Some other innovations are embedded in the development of tools that are being used in the APEX Program. The applications are for APEX but the development is really a part of fundamental engineering sciences. One example is the development of edge modeling

\footnotetext{
${ }^{5}$ This unpublished work and the figure shown were done by Kurani Gulec, then on staff at UCLA, and is archived on the APEX website (e.g., May Meeting, see Ref.1.). Some related work is continuing as part of graduate research being directed by Alice Ying and Neil Morley.
} 
to describe the interaction of the liquid surfaces with the edge plasma. This work is cited in References 26, 28 and 30 and was used to specify the heat loads for the heat transfer calculations summarized in Sections 4.2 and 4.3. Further descriptions of this work are included in articles elsewhere in this journal. ${ }^{6}$ Another example is the development of modeling and experiments on MHD effects in free surface flows. ${ }^{7}$ A third example is the development of a treatment for heat transfer in fluids, such as Flibe and Flinabe, that experience some MHD effects because they are weak electrical conductors and also can have enhanced heat transfer near the free surface due to the presence of waviness. Some results of this work are given in Sections 3.1.1 and 3.1.2 and in publications.[31-33]

\section{The Liquid Wall Chamber}

The mechanical and magnetic configurations for the liquid wall chamber are taken from an existing design study for a fusion power plant called ARIES-RS[25,26] with 16 toroidal field coils, a major radius of $5.5 \mathrm{~m}$, aspect ratio of 4 and fusion power of $2170 \mathrm{MW}$ D/T. However, for the liquid wall chamber design, a fusion power of $3840 \mathrm{MW}$ was specified to set more aggressive goals for power density, neutron wall load and heat removal. (Parameters were given previously in Table 1.) $430 \mathrm{MW}$ is radiated from the core; the balance flows into the edge plasma and is distributed between the first wall and the divertor and there are also large radiation regions near the X-point. The total power to the divertor is only $144 \mathrm{MW}$ and the peak heat load is $12 \mathrm{MW} / \mathrm{m}^{2}$.

This section presents the flow configuration. Subsequent sections present the heat transfer, energy conversion, materials and the mechanical design. Previous Fig. 1 shows a section of the chamber with the first wall, divertor and blanket. Figure 6 is a diagram of the temperatures of the Flinabe streams. The fluid (Flinabe) flows in two main circuits. One supplies the first wall and divertor and the other supplies the blanket.

\section{Flow Paths - First Wall}

The thin flowing first wall removes surface heat and protects the flow substrate, which is the front wall of the blanket structure, from this surface heat load. Figure 7 shows the flow path for the flowing liquid first wall. The inertia of the flow injected against the flow substrate keeps the stream against the convex substrate. There is a strong flow shear in the layer adjacent to the substrate and a fundamental question for this flow path is whether a stable flow can be established and maintained.

The working fluid for the first wall and blanket is Flinabe, a mixture of lithium, beryllium and sodium fluorides. Flinabe is a molten salt similar to Flibe, but has a lower melting point $^{8}$ that extends the window of operating temperature and a workable design appears possible.

The inboard and outboard first wall streams flow downwards from the top of the chamber. The first wall stream enters at $402^{\circ} \mathrm{C}$ and the bulk temperature rises to $422^{\circ} \mathrm{C}$

\footnotetext{
6 See the article "Design Integration of Liquid Surface Divertors," by R. Nygren et al. in this journal

${ }^{7}$ See the article ., "Modeling for liquid metal free surface MHD flow for fusion liquid walls" by N. Morley et al. in this journal

${ }^{8}$ The melting point is not well known and is the subject of experiments at Idaho National Engineering and Environmental Laboratory.
} 
at the exit from the divertor. The estimated maximum surface temperature of the first wall is $509^{\circ} \mathrm{C}$ and occurs at the bottom. At the bottom, these streams become the inboard and outboard divertor flow. Since a rapid flow for the blanket does not lead to a workable design for several reasons, this approach, with a single fast stream for the first wall and divertor, is the simplest implementation for the chamber flow, and we have tried to make this work in the APEX designs. Introducing a separate divertor stream offers the potential advantages of separate control for fluid parameters such as inlet velocity and temperature but also introduces the complexity of a separate flow loop.

A set of nozzles at the top of the chamber injects Flinabe streams onto the front surfaces of the blanket modules that guide the flow of the first wall. Each nozzle (Fig. 4 ) injects several fluid streams and is fed by a manifold. One set of nozzles feeds the inner first wall and another set feeds the outer first wall. The nozzles are "self-shielding" in that the overlapping streams prevent any line-of-sight from the plasma directly to a nozzle. The nozzle arrays distribute the flows uniformly in the toroidal direction. The streams must have sufficient velocity $(\sim 10 \mathrm{~m} / \mathrm{s})$ in the poloidal direction (down the first wall) to keep the surface temperature below some critical value based on the evaporation and must be relatively stable with respect to thickening or thinning as it travels from the top to the bottom of the reactor. The thickness of the first wall flow at midplane is $23 \mathrm{~mm}$.

The inboard wall flows vertically downward at $10 \mathrm{~m} / \mathrm{s}$ with no toroidal component that would tend to separate the flow from the inboard blanket surface. The outboard wall flows have both poloidal and toroidal components of velocity and both force the liquid against the guiding surface of the blanket. Each nozzle is canted at 20 degrees from the horizontal and 45 degrees to the radial plane. On an individual nozzle head, the inboard flow is injected below the outboard flow, and the outboard flow is split into a main stream, injected in the poloidal direction, and an auxiliary stream injected at an angle under the neighboring nozzle, to form an overlapping pattern. With this overlap, none of the nozzles are exposed (line-of-sight) to the plasma. Also, the outboard nozzle arrays have two tiers of nozzles aimed at slightly differing angles so that, as the radial distance increases, the streams "fan" out to alleviate any gaps.

\section{Flow Paths - Divertor}

The divertor collects and exhausts heat and particles. The streams from the inner and outer first wall become the streams of the inner and outer divertor. However, the features of the divertor flow differs from that of the first wall in three ways.

First, in the divertor, the toroidally continuous first wall flow must be separated at the sector boundaries and guided into the exhaust duct. In the outboard divertor, a deflector on the plasma-facing side of the stream (see Fig. 7) redirects the outer first wall flow downward to become the outer divertor stream. On the inboard side, the slight redirection needed is guided by the flow substrate (blanket surface).

Second, the flow in the divertor cuts across the magnetic flux surfaces to intercept charged particles, whereas the first wall is generally along one magnetic flux surface. Since the charged particles (carrying a high heat load) come in to the divertor surface at a grazing angle, any protrusion (like a surface wave) collects a large heat flux and "shadow" the region where these particles would otherwise deposit. Another effect is the 
MHD forces that arise from the radial and poloidal components of and gradients in the field.

Third, the peak heat load in the divertor is much higher than the first wall. The Flinabe thermally mixes as it passes through the deflector and then the surface temperature reaches a maximum of $\sim 610^{\circ} \mathrm{C}$ during the brief exposure to the peak heat flux of $\sim 12 \mathrm{MW} / \mathrm{m}^{2}$ in the divertor. The issues related to heat transfer are discussed further in Section 4.

Below the divertor, the inner and outer fluid streams join in the upper part of the exhaust ducts and flow out of the bottom of the chamber through this duct. The pumping duct is protected with a removable sleeve that also provides radiation shielding for the duct wall and magnets. The duct ( $1 \mathrm{~m}$ dia.) is large enough to carry the flowing fluid and provide sufficient conductance for pumping exhaust gases. For example, even if the flow velocity dropped from $10 \mathrm{~m} / \mathrm{s}$ in the divertor to $5 \mathrm{~m} / \mathrm{s}$ in the duct, the duct would only be $1 / 3$ full.

Flow Paths - Blanket

About $80 \%$ of the heat produced by the reactor is collected in the blanket. The flow must move through the blanket and provide cooling so that the temperatures in the beryllium multiplier and in the structure are well managed without local hot spots that would lead to degradation of the materials. The second fluid flow circuit is for the inner and outer blankets. Figure 8 shows a blanket sector and a cutaway of the blanket. The walls are made of an advanced ferritic steel. Behind the ferritic steel wall that forms the flow substrate for the first wall is a section of the blanket with beryllium balls. The beryllium is a neutron multiplier that increases the rate of tritium breeding in the Flinabe. Most of the interior space is an open volume for the flowing Flinabe. The inner blanket modules extend $7.5^{\circ}$ toroidally and the outer modules $4.5^{\circ}$.

The Flinabe enters at the back of the side channels of the blanket (from vertical pipes) at $402^{\circ} \mathrm{C}$ and flows (radially) along the sides to a $40 \mathrm{~mm}$ deep plenum between the front wall (first wall flow guide) and a bed of beryllium balls $100 \mathrm{~mm}$ deep. After passing through the beryllium multiplier the Flinabe temperature in the inboard blanket is $557^{\circ} \mathrm{C}$ and in the outboard blanket is $550^{\circ} \mathrm{C}$. The Flinabe exits at $646^{\circ} \mathrm{C}$ through a vertical pipe at the back of the blanket.

The radial build of the inboard blanket is $544 \mathrm{~mm}$; that of the outboard blanket is $644 \mathrm{~mm}$. Both have a $5 \mathrm{~mm}$ front wall, $40 \mathrm{~mm}$ Flinabe plenum and $60 \mathrm{~mm}$ beryllium bed $(57 \%$ packing density). In the main breeding region at the back of the blanket is $400 \mathrm{~mm}$ deep in the inner blanket and $500 \mathrm{~mm}$ deep in the outer blanket.

\section{Operating Temperature}

For a fusion reactor design with a liquid wall, the temperature window spans the lowest temperature, at the inlet to the chamber (same as the exit from the heat exchanger), to the highest temperature, found on the surface of the liquid facing the plasma as it flows down the first wall and down the divertor. This range of operating temperature that we call the "temperature window" must be consistent with some system that can convert heat into electrical energy (or some other end use) with reasonable efficiency. This is a basic issue for economic feasibility and depends primarily on two general features. 
The first is the span of the temperature window. This depends on the heat loads, flow rates and thermal properties of the liquid. This span must be sufficient for the (additive) temperature differences for (a) the local heat transfer $\left(T_{w}-T_{B}\right)$, i.e., the difference between the maximum temperature at the surface being heated and the coolest temperature in the adjacent bulk fluid that is absorbing the heat, and (b) the overall rise in coolant temperature from inlet to outlet $\left(\mathrm{T}_{\text {out }}-\mathrm{T}_{\text {in }}\right)$. For good power conversion efficiency, we need a large operating temperature window. For our liquid wall chamber, there is a further requirement that the fluid have a sufficiently low vapor pressure over this range and/or low melting temperature so that the source term for impurities evaporated from the walls ${ }^{9}$ still allows the desired conditions in the plasma. Impurity generation and its importance in this design work is discussed in the next section, specifically in Section 4.2 on heat loads and plasma edge modeling.

The second feature is minimum operating temperature, and this usually depends solely on the choice of fluid. The inlet coolant temperature $\left(T_{i n}\right)$ has to be significantly higher than the melting temperature of the reactor coolant. The obvious reason is so that the fluid does not freeze. There are also issues with the precipitation of solids in cold spots in some systems and with the (desirable) decrease in viscosity with increasing temperature above the melting point.

For our chamber design we selected Flinabe, a molten salt mixture of LiF, NaF and BeF2, as the liquid for the walls and blanket after previously finding that the temperature window for Flibe was too restrictive, as noted earlier. The material properties are very similar to Flibe, with the same BeF2 concentration at the same temperature. The key advantage is the melting temperature. The lowest reported melting temperature is $240^{\circ} \mathrm{C}$. However, the accuracy of this melting temperature is in doubt. A few compositions have melting temperature of around $300^{\circ} \mathrm{C}$, which is significantly below that of $460^{\circ} \mathrm{C}$ for Flibe. Since the maximum allowable coolant surface temperature is only $515^{\circ} \mathrm{C}$, (as will be discussed later), a melting temperature of $300^{\circ} \mathrm{C}$ will significantly increase the available coolant temperature window. The properties of Flinabe and Flibe are described further in Section 5 on materials.

The determination of the power balance based on modeling of the plasma edge as well as the basic alpha and auxiliary power that we have specified for this design (see previous Table 1) together with the considerations of energy conversion noted above are the basis for the flow rates and temperatures shown in Figure 7. This figure shows only the bulk average temperatures and does not give the peak surface temperature. The allowable coolant surface temperature, including the effects of sputtering and evaporation, is $515^{\circ} \mathrm{C}$. The heat loads along the first wall and divertor and the resulting surface temperatures are discussed in the next section and are consistent with these results. The results shown here and in the next section are the product of iterations in the design parameters to achieve as satisfactory balance and include considerations of the evaporation and sputtering, maximum allowable coolant temperature, and surface and nuclear heating.

\footnotetext{
${ }^{9}$ Since the first wall is closer to the main plasma, the maximum temperature of the wall, which sets the evaporation rate of impurities from the first wall, is one important limit. The maximum temperature in the divertor can be higher because the evaporated impurities there are more easily kept from the main plasma.
} 
An obvious concern as we considered a fast flowing first wall was that the coolant temperature rise $\left(\mathrm{T}_{\text {out }}-\mathrm{T}_{\text {in }}\right)$ in this stream would be very small. If the same volumetric flow rate were used in the blanket then the temperature window would be too small for a reasonable power conversion system. Our solution was to have only a small fraction of the first wall coolant $(5100$ of $27,000 \mathrm{~kg} / \mathrm{s})$ pass through the blanket and go to the power conversion system, while the remainder is recirculated. With this solution there is some parasitic "cost" in the power required for recirculation of Flinabe through the first wall (and a minor amount to the support structure), but overall we believe this is an effective solution. The Flinabe stream from the blanket heats to $646^{\circ} \mathrm{C}$, which is an attractive outlet temperature for power conversion. The blanket coolant flow was described in the previous section and shown in Figures 7 and 8. More detail on the coolant temperatures is given in the next section.

In obtaining the results summarized above and in the next section, we have concluded that a Flinabe-based liquid wall can (1) remove the large surface heat loads in a fusion reactor with high power density and (2) achieve an operating temperature window that is consistent both with reasonable chamber wall conditions for stable plasma operation and a balance of plant that has efficient power conversion.

\section{Heat Transfer}

A fifth of the power in a fusion reactor is deposited as a surface heat load to the chamber and a fundamental issue for high power density designs such as those being pursued in APEX is their power handling capability. In particular, the challenge is to balance the surface heat loads to the first wall and divertor. The "strike point" in the divertor is a very small area compared to that of the first wall and it is essential that the power carried into the divertor by a relatively small fraction of the total power for this heat load to be manageable in a compact fusion reactor. Relatively low power to the divertor then means that the first wall receives a large fraction of the particle power. A large heat load to the first wall can also be a challenge, for example due to high thermal stresses in a solid first wall. In our liquid surface chamber design, the flow path of the coolant (first wall) is the full length of the chamber wall, which is much longer than designs for solid walls, and the challenge is to keep the evaporation (impurity generation), and therefore the maximum surface temperature, at an acceptable level. Table 2 gives heat loads and flow rates for our Flinabe design.

These parameters define the general characteristics of the device. However, our calculations are not yet fully self consistent. For example, the fluid flow and heat transfer presented later are based on 2-D calculations that do take into account the effects of MHD on turbulence but ignore the expansion in the width of the flow stream as it moves down the chamber to regions of progressively larger diameter and the subsequent contraction of width in the lower hemisphere. Further work on such items is discussed in the later section on R\&D Issues.

\section{Heat Loads and Plasma Edge Model}

In our design, strong radiation from the core plus strong radiation from the divertor region is used to reduce the peak heat load in the divertor and balance the power loads of 
the divertor and first wall. The power to the first wall is $765 \mathrm{MW}$. This is $84 \%$ of the $909 \mathrm{MW}$ of total particle power while the balance of power to the divertor (144MW) is only $16 \%$. The ARIES design study[25,26] used "highly radiating rings" in the inboard and outboard divertors to reduce the direct heat load from particles onto the strike points of the divertors. The recent plasma transport modeling by Rognlien and Rensink, as yet unpublished, finds a stable operating window for a highly radiating edge plasma. Their recent results show steady state modeling solutions in which about $95 \%$ of the power coming into the scrape-off layer is radiated near the X-point for alpha powers in the range of $300-360 \mathrm{MW}$.

Plasma edge modeling with the 2D UEDGE code [26,28] provides the particle loads and the power deposition profiles for the first wall and divertor. The UEDGE modeling is complemented by that of Brooks using the BPHI-3D code, a sheath model with 3-D capability[30,34,35], to evaluate effects within the plasma sheath at the divertor and the WBC code[36] for near-surface transport of sputtered impurities. More descriptions of this modeling is given in elsewhere in this journal. ${ }^{10}$

Figure 9 shows the configuration of the UEDGE mesh and Figure 10 shows the heat load from radiation on the first wall and divertor from the UEDGE code for the Flinabe chamber design being presented here. The horizontal axis in Figure 10 is the length along the outer boundary in the UEDGE model that represents the free surface of the fluid. This path starts at the bottom of the inner divertor surface, goes up the surface of the inner first wall and then down the surface of the outer first wall and down the surface of the outer divertor. The peaks at the left and right are the higher heat loads on the inner and outer divertors, respectively. The radiative heat-load shown in Figure 10 is what heats the surface of the liquid as it flows through the chamber and gives rise to the evaporative flux of fluorine vapor. An iterative procedure is used to obtain the surface temperature consistent with the edge plasma conditions (see Sec. 4.2).

Figure 11 shows this key result of a highly radiating edge plasma using plots of the fluorine radiation density at four values of power $\left(\mathrm{P}_{\mathrm{c}}\right)$ convected from the plasma core to the edge plasma. Most of this power is then radiated to the first wall and divertor. For example, the condition for $300 \mathrm{MW}$ produced a peak heat flux (particle + radiation) at the divertor plate of only $\sim 8 \mathrm{MW} / \mathrm{m}^{2}$ and a peak heat flux to the first wall of $\sim 2 \mathrm{MW} / \mathrm{m}^{2}$ for a density at the edge of the core of $\sim 1.5 \times 10^{20} \mathrm{~m}^{-3}, \mathrm{H}(\mathrm{D} / \mathrm{T})$ throughput of $\sim 3.1 \times 10^{23}$ particles/s with divertor plates orthogonal to magnetic flux surfaces and $\mathrm{H}$ pumped at private flux surface for stability. The Fluorine density at core boundary varies poloidally over the range $3.7-7.3 \times 10^{17} \mathrm{~m}^{-3}(0.24 \%-0.49 \%$ of hydrogen; $1 \%$ is the limit based on core radiation loss). The impurity line-radiation is concentrated near the x-point and below, implying a lower maximum surface temperature for the first wall than for (assumed) uniform radiation. The power balance for this case is as follows:

Fluorine radiated power $=223 \mathrm{MW}$

Hydrogen radiated power $=63 \mathrm{MW}$ (reduced for reabsorption)

Particle power to divertor $=12 \mathrm{MW}$

Particle power to walls $=2 \mathrm{MW}$

10 See "Design Integration of Liquid Surface Divertors," by R. Nygren et al. in this journ al 
The set of four cases (left side in Fig. 11) shows a progression from a case that is not stable (MARFE), through two cases (300 and 400MW) with stable operation, to the 440MW case that is unstable and "burns through" onto the target. At the right of Fig. 11 is a later case $\left(\mathrm{P}_{\mathrm{c}}=480 \mathrm{MW}\right)$ with revised surface temperatures for the Flinabe and different plasma conditions, for which stable solutions were found with even higher convected power.

We must emphasize here an important caveat regarding the plasma edge modeling and the stability of such highly radiating edge-plasmas. An operating window exists, but outside this window, the edge impurities can either lead to a radiation collapse of the core, or become ineffective in the edge, thereby allowing a large particle heat-flux to reach the divertor. We consider cases where the highly radiating plasma is effective, and this has several implications for our design work. First, the liquid surface does present the potential advantage that this surface is regenerated in the event of a transient that results in excessive local heating that extinguishes the plasma. Second, it is reasonable to investigate designs based upon relatively modest peak heat fluxes $\left(8-10 \mathrm{MW} / \mathrm{m}^{2}\right)$ in the divertor as well as designs in which we maximize the peak heat flux that can be handled.

\section{First Wall Heat Transfer}

The surface temperature of the first wall increases from top to bottom as heat is added to the flowing Flinabe first wall over its long flow path of about $6.5 \mathrm{~m}$. Author Smolentsev has calculated the surface temperature along the flow path using a fluid flow and heat transfer model that includes MHD (magneto-hydrodynamic) effects. Typical output includes the flow thickness, quantities that characterize the turbulence and the velocity and temperature fields. The model has been described elsewhere.[37] Some results for our chamber design are summarized here.

The approach is based on the standard "K-_" model used widely in engineering applications to characterize turbulent flow. In the work for APEX, author Smolentsev and other collaborators have expanded the basic model to include the effects of MHD on the turbulence, particularly in the region of fluid near the free surface. The effect of MHD forces on the thickness (or speed) of the flow was also evaluated but there was little effect in the case of Flinabe. The effect on the heat transfer in the near surface was significant. In general in the presence of a strong magnetic field, the turbulent eddies in the bulk of the fluid tend toward a 2-D state with circulation around the direction of the magnetic field and elongation. in the direction of the field. Thus the turbulent structure is anisotropic, and near the free surface, there is also a damping of the turbulent transport. The other reason for anisotropy is turbulence redistribution near the free surface. This phenomenon occurs in the thin near-surface layer (known as a blockage layer) and caused by a blockage effect on turbulence due to the capillary forces and the gravity force component normal to the free surface. The blockage effect results in suppression of the velocity pulsations normal to the free surface and some enhancement of the other two velocity components due to continuity. Such turbulence redistribution near the free surface reduces heat transfer rate unless the surface waves enhance fluid mixing within the blockage layer. Thus, in these flows, one must characterize separately the turbulence in the bulk fluid and the turbulence near the free surface. 
The turbulence anisotropy at the surface can be characterized by the turbulent Prandtl number, which is the ratio of eddy diffusivity for momentum to eddy diffusivity for heat. Based on the experimental data for subcritical flows (Froude ${ }^{11}$ number $<1$ )[37], the distribution for the turbulent Prandtl number was evaluated. This distribution exhibits increase within the blockage layer when approaching the free surface. This differs radically from the assumed treatment for fluids like Flinabe in closed channel flows where the Reynolds Analogy is often assumed so that the turbulent Prandtl number is approximately unity and does not vary across the layer. In developing a solution for this problem, Smolentsev and collaborators incorporated Joule dissipation from both velocity and electric field pulsations in the treatment of the dissipation term in the equation for turbulent kinetic energy and destruction term in the equation for the dissipation rate and utilized the "K-_" model to characterize the eddy diffusivity for momentum as well as effective thermal conductivity across the liquid layer.

Freeze and Smolentsev[32] have also investigated the effect of waviness on the heat transfer of inclined thick flowing films appearing in supercritical flows (Froude number $>1$ ). Here the basic findings were a dependence of waviness (amplitude and wave length) on the component of the Froude number normal to the free surface and, with the free surface heated, an enhancement of the penetration of heat, i.e., lower surface temperature, due to waviness. Comparisons with predictions of a "K-_" model were made and improvements were developed through an expression for the near-surface turbulent Prandtl number evaluated from flow experiments done in a hydrodynamic test facility (FliHy) at UCLA.

Variations in heat flux along the flow length are treated by dividing the flow length into various zones, each with a specified heat flux, or by providing an analytical function that describes the heat load versus length along the flow path. The estimates of surface temperature for our Flinabe first wall, such as those in Figure 12, have typically been presented with two curves that bound the likely range of the surface temperature. Both calculations include the effect of the MHD on turbulence. The first curve, with a higher surface temperature, is calculated assuming no surface waves. The second curve, with a lower surface temperature, is calculated with the waviness effect and the corresponding distribution of the turbulent Prandtl number was evaluated from the experimental data for supercritical flows under conditions relevant to the reference case. Two curves are plotted because the impact of the magnetic field on the wave motion is still not clear. Although the experimental regimes were chosen to be close enough to the first wall flow in our design, the present experimental setup did not provide any measurements with a magnetic field. Therefore, the two curves in the figure give a possible range for the surface temperature. The upper curve corresponds to a flow regime in which all waves are suppressed by a magnetic field. The lower curve gives a temperature assuming the MHD has no impact on the surface waves. The true location of the temperature curve can be calculated if experimental data on wave suppression by a magnetic field become available in the future.

\footnotetext{
${ }^{11}$ The Froude number $\left(\mathrm{Fr}=\mathrm{V}^{2} / \mathrm{gD}\right)$ is a dimensionless scaling factor that arises from the gravitational term of the equation of motion. For Fr less than unity, gravitational effects are important in damping turbulence.
} 
As the Flinabe in the first wall flows down the upper half of the chamber, the radius of the chamber and the width covered by the flow increase until the mid-plane and then both decrease in the bottom half of the chamber. This change in width, and the corresponding thinning or slowing of the first wall flow, are not treated by the current 2-D version of the models developed.

Figure 12 shows the rise in temperature of Flinabe flowing down the outboard first wall with a starting thickness and flow rate of $23 \mathrm{~mm}$ thick and $10 \mathrm{~m} / \mathrm{s}$, an average surface flux of $1.76 \mathrm{MW} / \mathrm{m}^{2}$ and peak of $3.5 \mathrm{MW} / \mathrm{m}^{2}$ and an average nuclear wall load of $7 \mathrm{MW} / \mathrm{m}^{2}$ and peak of $10 \mathrm{MW} / \mathrm{m}^{2}$. (The neutrons produce volumetric (bulk) heating and the heating rate might typically be expressed in $\mathrm{W} / \mathrm{g}$ and would vary with the distance of the penetrating neutron flux; however, the convention here is to represent the power of the source term as a "neutron wall load" or power flux.) The penetration of the surface heat and nuclear heating contribute about equally to the rise in bulk temperature of $\sim 18^{\circ} \mathrm{C}$. The surface temperature profiles rise as the temperature gradient in the fluid develops over roughly $2 \mathrm{~m}$ of the flow length. The rise in surface temperature without the effect of waviness is $130^{\circ} \mathrm{C}$ and $90^{\circ} \mathrm{C}$ with the waviness. With an inlet temperature of $402^{\circ} \mathrm{C}$, the maximum estimated surface temperature of the first wall is $532^{\circ} \mathrm{C}$ when the potential advantage of the wavy flow is not taken into account and $492^{\circ} \mathrm{C}$ with waviness. Since we anticipate that some waviness will occur, we conclude that the maximum surface temperature will not exceed the allowable maximum surface temperature of $510^{\circ} \mathrm{C}$, and the first wall power handling is adequate.

\section{Divertor Heat Transfer}

The divertor heat load comprises a peaked heat load from charged particles hitting the surface at the "strike point" and a more uniform radiative heat load. The strike point is a toroidal band around the chamber on which the charged particles deposit as the follow the magnetic flux surfaces. The radiative heat load comes primarily from the strongly radiating zones near the null point in the separatrix. Charge exchange neutrals and radiation from the main plasma also contribute lesser amounts to the heat load.

Figure 13 shows a detailed view of the divertor heat load from the UEDGE model described previously with a peak heat load of only $10-12 \mathrm{MW} / \mathrm{m}^{2}$ in the outboard divertor. The figure also shows a flat profile with a peak heat flux of $10.6 \mathrm{MW} / \mathrm{m}^{2}$ that is the sum of the uniform radiated heat flux into the divertor of $\sim 3 \mathrm{MW} / \mathrm{m}^{2}$ plus the average of 7.6 $\mathrm{MW} / \mathrm{m}^{2}$ over the peak. Figure 14 shows the temperature rise in the divertor calculated by author Smolentsev for these conditions. Here the flow length is short and the contribution from nuclear heating is insignificant. The temperature rises rapidly within a short distance due to the high heat flux and generally poor thermal conductivity of the Flinabe. The rise in temperature is about $135^{\circ} \mathrm{C}$. This, added to the bulk temperature of $420^{\circ} \mathrm{C}$ leaving the first wall gives a peak of about $555^{\circ} \mathrm{C}$. This is higher than the allowable temperature of $510^{\circ} \mathrm{C}$ for the first wall, but is acceptable in the divertor where there is more shielding of impurities from the main plasma.

There are some differences between the heat transfer in the divertor and that for the first wall beyond the obvious one of a higher heat load in the divertor. In the top of the outboard divertor, the flow from the first wall impinges onto the deflector (see Fig. 15) and is directed downward, as shown in Fig. 7. Before receiving the peak heat load of the 
divertor, the fluid has passed the deflector, where thermal mixing of the fluid occurs. This mixing destroys the thermal gradient in the first wall flow and the flow stream leaving the deflector to become the divertor flow has an approximately uniform temperature equal to the bulk temperature from the first wall stream. Fig. 15 shows some of the details of the deflector, such as vanes to direct flow.

The flow initially exiting from the deflector also has a somewhat higher turbulence in the layer near the free surface than in the layer upstream of the deflector. This enhances the heat transfer. An issue in designing the divertor was how to minimize the peak surface temperature, and, in this regard, having the peak heat load close to the deflector was investigated.

Figure 16 shows profiles of the turbulent viscosity versus the normalized distance from the back (flow substrate) to the free surface at several locations downstream from the deflector. A substrate must be present in this model, so there is a continuing source of drag to promote turbulence at the back surface. However, the right side of the plots gives some sense of how the turbulence decays from an initially higher value toward that of a developed free surface.

In Figure 17 are temperature profiles for several position of the peak heat on the divertor stream. As the location of the peak heat load gets further from the exit of the deflector, the peak temperature is higher. The increase in peak temperature with distance from the deflector exit is roughly linear with a slope of $\sim 32^{\circ} \mathrm{C}$ increase in surface temperature for each $0.1 \mathrm{~m}$ increase in distance from the peak heat load to the deflector exit. So the proximity is important and the general approach of keep the peak heat load within $\sim 0.2 \mathrm{~m}$ of the deflector exit is a good guideline. This increase is due both to the heating of the stream from the $3 \mathrm{MW} / \mathrm{m}^{2}$ heat load before the peak heat flux is encountered and to the lessening of turbulence near the free surface. The roughly linear dependence of the increase on distance is actually the sum of a less than linear increase in the pre-heating and a more than linear increase due to the lessening turbulence.

A peak heat load of $11.7 \mathrm{MW} / \mathrm{m}^{2}$, slightly higher than in Fig. 13, was used in the heat transfer calculations for the divertor. The increase takes into account local shaping in the divertor and (toroidal) openings for particle pumping. The model described in the previous section was also used to calculate the temperature rise in the divertor.

Another aspect of heat transfer in the divertor is the cooling of the deflector itself, which receives a heat load of $3 \mathrm{MW} / \mathrm{m}^{2}$ from the plasma. While most of the area on the back of the deflector is in contact with the flowing Flinabe, there must be a lip at the upstream entrance to catch any waves. This lip receives the same heat load but must conduct this heat along the lip of the deflector to the area that is cooled by the Flinabe. An initial thermal analysis of the deflector indicated that (a) the deflector should be made of a good thermal conductor and (b) the lip should be thick to increase its thermal conductance. For a 100-mm-long lip a 2-D thermal analysis indicates a problem with the very end of the lip where the temperature reaches $\sim 900^{\circ} \mathrm{C}$. The material is copper clad with a thin layer $(0.5 \mathrm{~mm})$ of advanced ferritic steel. The more likely design solution, not yet done, is to cool the lip by forced convection in an internal channel for Flinabe that runs inside the lip. 
A further concern for the heating of the divertor is the "leading edge" problem. Charged particles at the edge of a plasma follow the magnetic field lines and will deposit a tremendous heat load on any protrusion that has intercepted this particle flux. When we imagine that the divertor is a continuous and smooth toroidal surface, these particles (and their energy) are spread evenly over this surface. But when a toroidal opening exists, some particles diffuse radially outward in this gap and would impinge "head on" onto the edge of the opening. This circumstance can produce very high local heat loads. The techniques for mitigating this is to make the plasma-facing surface near these leading edges gradually recede so that the diffusing heat load spreads over this larger receding area. For the liquid stream in the divertor, this simply means that deflector is shaped so that the region at the sides of the stream for a particular sector are slightly further out in radius at the location of the peak heat flux. The divertor shape and cooling of the lip are discussed further in out companion article. ${ }^{12}$

\section{Blanket Heat Transfer}

Heat is generated in the blanket as the result of nuclear heating. Neutrons $(14.1 \mathrm{MeV})$ produced in the core plasma from the fusion reaction penetrate the first wall and blanket and dissipate energy through scattering, deposit energy when stopped and undergo nuclear reactions with $\mathrm{Be}$ and $\mathrm{Li}^{7}$ that produce other neutrons. The heat in the blanket is removed by flowing Flinabe, as indicated in Figures 6 and 8. A subsequent section of this paper covers the tritium breeding in the blanket and also gives more details on the radial build of the blanket and nuclear heating. Here we summarize the coolant temperatures and pressure drops. (see Table 3.)

\section{Materials}

In the design effort in APEX on chamber technology with liquid walls, we have investigated Flibe and Flinabe and several liquid metals, as noted previously. For the design presented here, Flinabe is the material for the flowing first wall and divertor and the breeder and coolant for the blanket design. The primary structural material for the blanket, and auxiliary structures, is an advanced ferritic steel. The front and side walls of the blanket are 5mm thick. The back wall is thicker. The blanket also utilizes beryllium in the form of a bed with $5 \mathrm{~mm}$ beryllium pebbles as a neutron multiplier.

\section{Flinabe}

The motivation in selecting Flinabe as a working fluid was that it had a melting temperature lower than Flibe. We had evaluated Flibe earlier as a possible working fluid and found a problem with the operating temperature window. The molten salt Flinabe is a mixture of three fluorides; the nominal 1:1:1 mixture is LiF-NaF-BeF2. The neutronics characteristics of Flinabe and tritium extraction are described later in sections.

We have little data on the physical properties of Flinabe, but we believe these are similar to another molten salt, Flibe, but with a lower melting temperature. Flibe is a mixture of $\mathrm{LiF}$ and $\mathrm{BeF}$ that was studied for use in molten salt fission reactors (and actinide burners) but much of the data are in laboratory technical reports.[38-40] Good data compilations also were done in the past for the HYLIFE-II study[41], a heavy-ion driver inertial fusion

12 See "Design Integration of Liquid Surface Divertors," by R. Nygren et al. in this journ al. 
power plant, and for the Blanket Comparison and Selection Study[42]. There has also been a recent assessment of Flibe that discusses its chemistry and the issues associated with tritium processing.[45]

In the past, researchers in Russia and others at Oak Ridge National Laboratory have performed some investigations of Flinabe. These were investigations of specific mixtures in a ternary system and the data are limited and there are questions. For example, one phase diagram noted a melting temperature of $240^{\circ} \mathrm{C}$ for a salt mixture but a typo was suspected.

Our conclusions based on a review of these data are as follows.

1. There may be mixtures of Flinabe that have melting temperatures below $300^{\circ} \mathrm{C}$; this should be investigated in new experimental work.

2. Based on a binary phase diagram of the mixture Na2BeF4 and Li2BeF4 by Toropov, there appears to be a salt mixture of $30 \% \mathrm{Na} 2 \mathrm{BeF} 4$ and $70 \% \mathrm{Li} 2 \mathrm{BeF} 4$ (a ternary mixture of $20 \% \mathrm{NaF} 47 \% \mathrm{LiF}$ and $33 \% \mathrm{BeF} 2$ ) with a melting temperature of $\sim 290^{\circ} \mathrm{C}$. This is a reasonable basis for an assumption of a useful Flinabe mixture with a melting temperature as low as $290^{\circ} \mathrm{C}$.

3. The minimum temperature must be sufficiently above the melting temperature to provide a margin of safety against freezing.

We are using the thermo-physical properties of Flibe for our heat transfer calculations. Basically Flibe is a poor electrical and thermal conductor with a thermal conductivity of about $1 \mathrm{~W} / \mathrm{m}-\mathrm{K}$. A high flow rate and turbulent heat transfer are necessary to accomplish the heat transfer in our design. Its viscosity is rather high (kinematic viscosity of $11 \times 10^{-6}$ $\mathrm{m}^{2} / \mathrm{s}$ ), about an order of magnitude greater than water, so the pressure drops through piping is a concern and large passages are desirable.

The evaluations of the compatibility of Flibe with an advanced ferritic steel indicate an allowable interface temperature of up to $700^{\circ} \mathrm{C}$. Chemistry control of the formation of HF will be needed either within the blanket or in the balance of plant. This requires an excess of beryllium in contact with the Flibe (or Flinabe) to stabilize the fluoride in the salt.

Flinabe has a low solubility for tritium. This makes the recovery of tritium from Flinabe easier but means there is a relatively high partial pressure of tritium in the primary Flinabe loop that can drive tritium permeation (see later section, Tritium Processing).

\section{Structural Material}

Various structural materials have been and are being investigated and considered for fusion applications. $[45,46]$ An advanced ferritic steel was selected as the structural material. This class of materials has been identified as attractive in the fusion program for the following reasons.

1. We believe such materials can be produced with compositions that result in low activation.

2. Radiation experiments have shown that such alloys have low swelling.

3. Recent developments with oxide-dispersion-strengthened (ODS) ferritic alloys have produced alloys with comparatively high strength and creep resistance to temperatures 
approaching $800^{\circ} \mathrm{C}$; whereas the mechanical properties of previous ferritics declined above $550^{\circ} \mathrm{C}$.

Features 1 and 2 above have been known for some time and ferritic steels have been considered in the past as potential structural materials for fusion blankets. It is really the recent developments in the ODS ferritic alloys[47,48] and the extension of good mechanical properties to significantly higher temperature that are now bringing renewed interest to the application of ferritics in fusion. One formulation of an ODS ferritic steel being developed at Oak Ridge National Laboratory and designated 12 YWT has $0.25 \%$ of Yttria and superior properties.[47] It appears to have a maximum working temperature of $800^{\circ} \mathrm{C}$ and corresponding yield strength of $320 \mathrm{MPa}$. When used with the molten salt coolant Flibe, the two materials are compatible up to $700^{\circ} \mathrm{C}$.

The material is new and still being developed. As yet there remain issues in regard to methods for making large production lots and fabricating and joining this material. These issues are discussed further in the later section on R\&D issues. Also, there is further discussion of the use of advanced ferritic steels elsewhere in this journal. ${ }^{13}$

\section{Other Materials}

A complete reactor design would specify the materials needed for the shielding, magnets and auxiliary components. However, the focus of our effort in APEX is on the chamber technology. One class of materials that we do note here is ceramic coatings. We have identified the need for two such applications, described briefly below, in our design work. The potential needs for coatings in various fusion applications is recognized and has been recently reviewed.[49]

Some designs with flowing liquid metals use ceramic coatings between the flowing metal and the channel or substrate. The coating provides electrical insulation that forces MHDinduced currents to close within the liquid metal rather than through the walls of the channel or substrate. Typical objectives in such applications are the reduction of the pressure drop in a channel or the reduction of flow asymmetries, such as jets or stagnation in side layers. Another application, specific to (poloidally) flowing liquid metal walls is the possible need for insulating fins at a few toroidal locations to interrupt the path for full toroidal electrical currents in the liquid wall. These applications are noted here simply for completeness because designs with liquid metal walls have been considered in APEX. The need for such insulators has been recognized in the fusion program in work on designs with liquid metals in closed channels, but effort within APEX has not been directed to this area.

Another application is for coatings that can reduce the permeation of tritium. This is a concern for various blanket designs. In our design with Flinabe and a relatively high partial pressure of tritium in the primary Flinabe loop, we specify a ceramic coating on the inside of the piping in the primary heat exchanger to reduce the tritium permeation

\footnotetext{
${ }^{13}$ See "Molten Salt Self-Cooled Solid First Wall and Blanket Design Based on Advanced Ferritic Steel" by Wong et al. and "Solid wall recirculating blanket: geometry, materials, materials compatibility, structural evaluation, fabrication and fluid circuits" by Sviatoslavsky et al.
} 
from the primary loop into the molten salt loop for the secondary heat exchanger. (See a later section, Energy Conversion, for further information.)

\section{Mechanical Design}

The mechanical design has been developed by authors, Nelson, Fogarty and Eberle to the point that we can see that the design integration of the sectors and piping systems, manifolding, etc. is self-consistent, that the sizes and locations of the piping and ducts are reasonable in terms of the pressure drops, and that the components are amenable to handling for remote maintenance. Experienced designers have done this work and we anticipate that the designs can be made robust in terms of the mechanical and EM (electromotive) forces that such a structure must withstand. The objective of this work is to develop a nominally workable design for the chamber technology. We have not had the time nor resources to develop the full engineering details that would show the mechanical response of the structure to various types of off normal events and transient loading that are associated with a detailed engineering design and safety analysis.

\section{Overall Structure}

The solid mechanical structure of the chamber consists of the modules listed in Table 4 and their associated piping and support. There are 16 toroidal field coils and therefore 16 openings between the Dewar for the superconducting coils. (See previous Fig. 8.) The number of blanket modules is determined by various design constraints, such as the routing of piping, arrangements for manifolds and the size and weight that can be handled during remote maintenance.

The CAD views by author Fogarty in Figures 18 and 19 show the various blanket modules and how they are nested together during assembly of the chamber. The piping systems from the modules extend past the shield modules. The vacuum boundary for the chamber, excluding the piping penetrations and those for the large exhaust ducts, is the outer envelope of the shield modules and the (radially) outboard portions of the outboard blanket, divertor and nozzle modules. Welded joints between these modules and the shield modules and between adjacent shield modules provides the vacuum seal.

Each blanket module consists of a back plate, an outer shell fed by two Flinabe inlet pipes, and an inner volume. The dimensions are given in previous Figure 8 . The Flinabe enters the inner volume by first flowing through a $60 \mathrm{~mm}$-thick bed of $5 \mathrm{~mm}$ diameter beryllium pebbles and passing back into the large inner reservoir and eventually to the outlet pipe.

A big challenge in the design of solid fusion chambers (solid first wall and blanket) is dealing with typically high stresses in the first wall that result from the surface heat load, necessary cooling and the associated thermal gradient. In our design, this challenge is substantially mitigated because the liquid first wall intercepts and carries away this surface heat load.

There are also thermal stresses in the blanket but these are less severe than in a solid first wall. The blanket modules design provides for flexure of the inner and outer side walls to relieve stress. The front and side walls are $5 \mathrm{~mm}$-thick advanced ferritic steel. 
However, there is always a concern with the constraint where the side walls join to the top or bottom, and there is a thermal gradient across the inner wall that divides the hotter Flinabe from the inlet flow. Based on experience from other designs, we do not anticipate a problem, but we have not yet performed the 3-D thermal and stress analysis of the structure to confirm this opinion.

\section{RF System - An Example of Wall Penetrations}

Our chamber design provides cassettes for RF heating and current drive systems as shown in Figure 19. These penetrations of the first wall present the challenge of diverting the first wall flow, and we have tried to identify a representative RF system to include in the design integration of the chamber. RF power launching structures and diagnostics will both probably require wall penetrations. The diagnostics are unspecified at this point but we are assuming that the approach described here will be adequate. Fusion reactor designs often include many types of RF heating (ECH, ICRF and LH) because this provides the most versatility, and at this point in time, we are unsure of what exactly will be needed.

ECH (electron cyclotron heating) requires a wave guide and "free space" launch, i.e., the antenna does not have to conform to the shape at the edge of the plasma and can be fairly compact. For current drive with $\mathrm{ECH}$, the launchers are typically placed at the top of the device near the null point and the launched power density is $\sim 100 \mathrm{MW} / \mathrm{m}^{2}$. ICRF (ioncyclotron) antennas are placed at the plasma edge. The penetration is a small coaxial lead. For current drive, ICRF antennae can be placed in any poloidal location. The typical launched power density is $\sim 10 \mathrm{MW} / \mathrm{m}^{2}$. The most stringent requirement appears to be that the grills for lower hybrid heating $(\mathrm{LHH})$ that must be in fairly close proximity to the plasma. The typical launched power density is $50-60 \mathrm{MW} / \mathrm{m}^{2}$ and $88 \mathrm{MW} / \mathrm{m}^{2}$ (used in ARIES) is not a large extrapolation.

Although including all types of RF heating provides the most versatile option, we have elected a more restricted set consisting of $\mathrm{LHH}$, for the edge to compensate for excess current in the core, and ECH for core current drive. Our assumption is that a viable ignition scenario could be developed with ECH and LHH, e.g., heating of a low-density plasma followed by an increase in density. Our approach here has been to identify the types of systems that are likely to be needed and include these in the design configuration; however, there is no self-consistent physics basis with which to estimate the required RF power. We have taken nominal values of $80 \mathrm{MW}$ for the $\mathrm{ECH}$ core current drive and 12MW for the LHH system to counter excessive currents at the edge (edge overdrive) that may result from the $\mathrm{ECH}$. The parameters are given in Table 5.

The basic requirement for penetrations is that the fluid path in the first wall has to be redirected around the penetration without causing splashing of fluid into the plasma edge. Our example in this regard is a large penetration near the mid-plane for the RF cassettes shown in Fig. 19. We anticipate that the technology for the smooth flow around penetrations can be managed by a combination of flow separation and wall shaping above the penetration and auxiliary nozzles at the bottom of the structures so that the downstream "hole" in the wake of the FW fluid flow can be filled with the added fluid. The nozzle system could be incorporated as the outlet for any necessary cooling passages 
within the structure itself. Some initial work was done on the wall shaping and is discussed in the later section on R\&D Issues.

\section{Piping}

The inlet and outlet pipes and manifolds for one sector are evident in Figure 18. The pressure drops for the flow paths were calculated and found to be acceptable. The piping arrangement consists of several separate sets of pipes.

The first set supplies the liquid first wall itself and consists of separate pipes for each inboard and outboard nozzle array. The first wall (and divertor) flow exits via the pump ducts; these ducts carry the total first wall flow into a reservoir from which it is pumped through a heat exchanger and then back to nozzle array for the first wall.

There are separate piping systems for the internal cooling of each divertor cassette and of each heating or diagnostic cassette.

\footnotetext{
Each blanket can-is fed from two supply pipes at the bottom of the sector. The pipes are routed and shaped to maintain bulk shielding while providing space for the liquid wall drain system. This is particularly challenging for the inner blanket modules. For these the individual inlet and outlet manifolds have multiple inlet or outlet pipes, and the nested array of the individual pipes to and from the upper middle and lower cans (separated fluid containers) to the manifolds of a single inner blanket module is designed to minimize both the radial space and the void volume needed. Table 6 is a piping chart showing sizes, quantities, flow rates, temperatures, etc.
}

\section{Maintenance}

The chamber components may be classified as high maintenance, low maintenance and "lifetime" based on the expected reliability and/or frequency of replacement. The maintenance scheme for each general classification is described below.

\section{High Maintenance Components:}

Those components considered most likely to fail during operation (liquid supply systems, film formers, heating elements, diagnostics devices, and divertors) and designated as high-maintenance items and were designed as removable cassettes. The RF modules and nozzle and divertor cassettes shown in Figure 19 are examples.

To increase the availability factor of the machine, it is imperative that these high maintenance components can be rapidly replaced without having to disassemble the entire device. For example, each nozzle array is contained in a cassette that can be removed and replaced independently from the rest of the reactor internals. The cassettes and nozzles will be exposed to high neutron fluences, and the nozzles and internal piping are subject to erosion and degradation from the high velocity flow. Frequent replacement of the film forming cassettes, perhaps as often as once every two years, is assumed.

\section{Low Maintenance Components}

The low-maintenance items, e.g., the blanket/shield modules, are extremely heavy and not designed to be remotely maintained or remotely transported. For their infrequent maintenance, a total sector is removed. Previous Figure 8 shows a sector, Figure 18 shows blanket modules and Figure 19 shows the blanket modules nested in the shield module.

There is insufficient clearance, and not really even an open pathway, either through the back of the blanket nor the top of the liquid supply system, to extract large components. Consequently, access to the blanket modules requires removal of a whole sector. Since 
the outboard blanket and shield would have to be removed first anyway to gain access to the inboard components, removing a sector module intact is easier and faster and provides the needed access (in a hot cell) to all components for necessary repairs and scheduled maintenance.

Another concern that justifies the approach of removing entire sectors for access to low maintenance components is the possibility, and perhaps the likelihood, that at some time, leaks or damage might result in these large components, such as blanket modules, sticking to each other or to the shield module. An alternative of removing individual modules remotely rather than a whole sector, presents the risk of one or more of the following undesirable circumstances. First, the component itself could be damaged or destroyed during the attempted extraction. Second, adjacent components might be damaged. Third, the process of dealing with these damaged components and completing their extraction and any necessary repairs and cleanup to the remaining structure would likely take the device out of service for an extended period.

Thus, we believe it is prudent to do all major repairs of non-cassette components outside of the machine in a hot cell room. While such repairs occur, a replacement sector would be installed.

\section{Lifetime Components}

The vacuum vessel and coil sets are considered to be lifetime components and therefore need to be protected with adequate shielding. If repairs are required, the shielding minimizes the neutron damage to the vessel material and makes it possible to cut, remove, replace, and re-weld sections of the vessel. This procedure follows the sector removal process.

\section{Neutronics}

In the molten salt LiF-NaF-BeF2 (Flinabe) the Li atom is in one of three fluoride molecules and its tritium breeding capability is less than that of LiF-BeF2 (Flibe), in which $\mathrm{Li}$ is in one of two molecules. The lower $\mathrm{Li}$ concentration requires a comparatively greater amount of neutron multiplier (beryllium) to improve the tritium breeding ratio (TBR). Author Youseff here shows these characteristics for two types of structural materials, namely $\mathrm{SiC}$ and ferritic steel (FS-HT-9) in the initial CLiFF configuration, which was used earlier for assessment of TBR with other liquid breeders[50-54]. The TBR in the final blanket configuration with advance ferritic steel (AFS- Nanocomposite Ferritic NCF) structure, as well as other characteristics of the final design, such as nuclear heating and requirements for shielding are given in this section.

\section{Tritium Breeding - Initial Assessment}

The radial build of the initial APEX liquid surface chamber design concept is shown in Table 7. One-dimensional model was used in the analysis where both the inboard (IB) and outboard (OB) are accounted for. The ANISN 1-D[55] code was used along with 46 neutron-21 gamma multigroup data library based on the FENDL-2 data[56]. The plasma and FW radii are those used in the ARIES-RS design[57]. The front flowing liquid layer (FFLL) is $2 \mathrm{~cm}$-thick followed by $0.5 \mathrm{~cm}$-thick wall that is the flow substrate for the first wall flow and $60 \mathrm{~cm}$-thick blanket on the $\mathrm{OB}$ side (40 cm-thick on the IB side). The vacuum vessel, shield and magnets are considered in the calculational model to account 
for neutron economy. The blanket consists of $90 \%$ breeder/coolant and $10 \%$ structure. The shield is composed of $95 \%$ structure and 5\% breeder/coolant. Tritium breeding takes place in both the blanket and shield.

Significant increase in local TBR is achieved upon including a neutron multiplier zone in the blanket. This is shown in Fig. 20 where local TBR is calculated as a function of the thickness of the front beryllium zone. This zone consists of $60 \% \mathrm{Be}, 30 \%$ breeder, and $10 \%$ structure. The results shown in Fig. 20 for Flinabe and Flibe are based on the values of Li-6 enrichment for which TBR reaches its maximum value (in the absence of $\mathrm{Be}$ ) when either ferritic steel or $\mathrm{SiC}$ is used as structure.[58]

For the same beryllium zone thickness, TBR in Flinabe is less than in Flibe by $\sim 4-7 \%$ in the ferritic steel structure case and by $5-9 \%$ in the $\mathrm{SiC}$ case. To achieve the same TBR in Flibe, additional 3-4 cm of beryllium zone is needed with Flinabe (for both structures). For example, to achieve tritium breeding ratio of 1.4, the required beryllium zone thickness $\square(B e)$, is shown in Table 8. Note from the Table that replacing steel with $\mathrm{SiC}$ requires increasing the Be zone thickness by $\sim 1 \mathrm{~cm}$ in order to achieve the same TBR. Since beryllium occupies $\sim 60 \%$ of the multiplier zone, the effective beryllium thickness, $\square_{e}(B e)$, is less as shown in Table 8.

\section{Tritium Breeding Final Assessment}

The latest APEX blanket configuration included a $4 \mathrm{~cm}$ thick breeding zone following the $2 \mathrm{~cm}$-thick FFLL and the $0.5 \mathrm{~cm}$-thick solid wall. This zone was modeled to account for the Flinabe coolant entering the blanket zone and routed from the FW. The advanced Ferric steel (AFS/NCF) is used as the structural material and shield. The beryllium zone composed of $4 \% \mathrm{AFS}, 57 \% \mathrm{Be}$, and $39 \%$ Flinabe where as the breeding zone is composed of $4 \%$ AFS and $96 \%$ Flinabe. The total blanket thickness (front Flinabe zone + Be zone + back Flinabe Zone) is kept at $60 \mathrm{~cm}$ and $40 \mathrm{~cm}$ on the $\mathrm{O} / \mathrm{B}$ and I/B side, respectively, as shown in Table 6 . In this more realistic configuration, the TBR as a function of the breeding zone exhibits lower values which are shown in Fig, 21. For a $12 \mathrm{~cm}$-thick Be zone, the local TBR is $\sim 1.3$ and is 1.4 at $\sim 28 \mathrm{~cm}$-thick Be zone. The local value adopted in the present design is TBR 1.22 at a thickness of the beryllium zone $\square(B e)=6 \mathrm{~cm}$ ( $57 \%$ dense) which is equivalent to an effective beryllium thickness $\square_{e}(B e)=3.4 \mathrm{~cm}$. The corresponding TBR $(\sim 1.22)$ is used as the reference value and believed to be adequate in meeting tritium self-sufficiency goal.

\section{Nuclear Heating and Shielding}

Nuclear heating (from both neutrons and gamma rays) have been estimated throughout the APEX liquid wall (LW) configurations with Flinabe as the coolant and breeder. The power multiplication (ratio of power in all components to incident neutron power) is shown in Table 9 for the initial and latest liquid surface chamber designs. About $31 \%$ of the total nuclear heat is deposited in the I/B whereas the balance $(\sim 69 \%)$ is deposited in the $\mathrm{O} / \mathrm{B}$ at the mid plane. The contribution to the total heating from each component is shown in Table 10. The power deposited in the front flowing liquid layer is $\sim 12-14 \%$ whereas most of the power $(\sim 80-83 \%)$ is deposited in the blanket (excluding the solid FW). 
The required minimum shield thickness, both in the inboard and outboard side, was estimated such that the upper limits to radiation damage to the magnet will not be exceeded. This optimization is needed to eliminate oversized shield and thus reduce cost. This also will allow for more space, particularly on the inboard side, for manifolds and piping to route coolant. The upper limits to radiation damage to the magnet consodered in the analysis are: (1) end-of-life fast neutron fluence $(\mathrm{En}>0.1 \mathrm{MeV})$ of $1.0 \times 10^{19} \mathrm{n} / \mathrm{cm} 2$, (2) end-of-life insulator (glass-fiber-filled, GFF, polyimide) dose of $1.0 \times 10^{9}$ Grays $\left(1.0 \times 10^{11} \mathrm{rads}\right),(3)$ end-of-life copper stabilizer of $6 \times 10^{-3} \mathrm{dpa}$, and (4) Peak winding pack power density of $2 \mathrm{~mW} / \mathrm{cm}^{3}$.

Table 11 gives the minimum shield thickness required on both the inboard and outboard side. The good radiation attenuation characteristics of Flinabe resulted in thinner shield. The minimum shield requirement is driven by the limit on the end-of-life neutron fluence. As shown in the Table, this minimum shield is $\sim 56 \mathrm{~cm}$ in the inboard side and $\sim 26 \mathrm{~cm}$ in the outboard side. With this shield thickness, the vacuum vessel can last the plant lifetime (30 years). Note that the total shield thickness in the I/B shown in Table 7 is $\sim 55 \mathrm{~cm}$ (342-314 LT-shield + 371.5-344 HT shield) which is just enough to meet the requirement there. The total shield thickness in $\mathrm{O} / \mathrm{B}$ shown in Table 7 is $\sim 60 \mathrm{~cm}$. It can thus be reduced to $\sim 26 \mathrm{~cm}$ with substantial saving in the cost of magnet protection on the outboard side.

\section{Attenuation of X-rays from Bremmstrahlung Radiation}

Because the radiation from the plasma is incident on a liquid layer, as opposed to solid material in solid FW concepts, $\mathrm{x}$-rays from bremmstrahlung radiation can deposit its power over a measurable length in the liquid layer. This depends on the penetration length which is a function of both incident x-rays energy and the liquid material under consideration. Figure 22 gives the penetration length (mean free path) of x-rays in several materials as a function of the incident photon energy. As shown, lithium is the best candidate for depositing the surface heat over a longer depth. The penetration for Flinabe is similar to Flibe which shows that power from surface heating can be spread over a measurable depth in the front Flinabe layer. This was accounted for when the inlet and exit temperature of the front flowing layer were calculated. More on the attenuation of x-rays can be found in Ref. [58]. 


\section{Radioactivity, decay heat, and radwaste}

Author Sawan performed activation calculations for the Flinabe blanket in the APEX liquid wall concept to determine the generated radioactive inventory and decay heat. The detailed results used for the safety assessment are included in another article ${ }^{14}$ in this journal.

Figure 23 shows the total activity generated in the blanket constituents as a function of time following shutdown. The Flinabe activity is dominated by ${ }^{16} \mathrm{~N}\left(\mathrm{~T}_{1 / 2}=7.13 \mathrm{~s}\right)$ for up to a minute after shutdown and by ${ }^{22} \mathrm{Na}\left(\mathrm{T}_{1 / 2}=2.605 \mathrm{y}\right),{ }^{24} \mathrm{Na}\left(\mathrm{T}_{1 / 2}=14.96 \mathrm{~h}\right)$, and ${ }^{18} \mathrm{~F}$ $\left(\mathrm{T}_{1 / 2}=1.83 \mathrm{~h}\right)$ at later time. The total Flinabe activity is less than the total structure activity except for the first minute after shutdown. The total ${ }^{24} \mathrm{Na}$ activity is much lower than the total structure activity and is expected not to be a major concern when Flinabe is used in fusion systems.

Figure 24 gives the decay heat results. Decay heat generated in the Flinabe is much larger than that generated in the NCF structure and should be a concern during a loss of flow accident (LOFA). The waste disposal rating (WDR) of the structure in the CLiFF blanket is $<0.8$ and is contributed primarily by ${ }^{94} \mathrm{Nb}$ produced from transmutation of Mo. In addition, the Flinabe and Be WDR values are well below unity $(<0.004)$. Hence, all blanket components will qualify as Class C low level waste.

\section{Tritium Processing}

The fundamental requirement for tritium processing is to recover tritium bred in the breeding material efficiently to provide the fuel for the reactor. Tritium has a very low solubility in both Flibe and Flinabe. The Henry's law constant is only $7 \times 10^{-5}$ moles$\mathrm{H}_{2} /$ liter-atm[59]. Using this solubility, along with the rates of tritium production and flow and temperature of Flinabe given previously, Author Sze calculates that the tritium partial pressure over the Flinabe to be about $40 \mathrm{~Pa}$ at the exit of the reactor. This is an exceeding high tritium partial pressure, so the tritium recovery from the Flinabe will not be a technical issue. However, the high partial pressure makes tritium control a challenge.

Gas purging is the easiest method for recovering tritium from Flinabe, and a vacuum disengager process is proposed for this purpose. A key step in the process is using a vacuum system to pump tritium from the molten salt coolant. Although this process was proposed for Flibe, it can certainly be used to recover tritium from Flinabe.

The tritium permeation rate in the primary heat transfer system was calculated by TMAP code as noted in the next section. Without mitigation, the high tritium partial pressure over the Flinabe loop in this system will drive tritium permeation into the power conversion system. We address this in our design with the following features. We use a ceramic coating on the inside of the piping of the primary loop in the primary heat exchanger. Such a system has been evaluated for the molten salt reactor program. We also specify a secondary molten salt heat exchanger to provide further isolation and reduction of tritium available for permeation into the steam generator. Again, such a

\footnotetext{
${ }^{14}$ See "Safety Assessment of Two Ferritic Steel Molten salt Blanket Design Concepts" by B. Merrill et al. in this journal.
} 
system, with a floural boral nitride salt, was design for use in the molten salt reactor program.

The tritium permeated into the secondary molten salt coolant can be removed by a secondary recovery system. In the purging systems, molecular sieves can be used to recover tritium from helium in a helium loop. Water distillation with vapor phase catalyst exchange can be used to recover tritium from water. The leakage rates from secondary coolants are important factors in assessing the feasibility of tritium recovery from the secondary loops. If the leakage rates are high, the allowable tritium concentration in the secondary coolants will be low, and the coolant process rates for secondary tritium recovery will be high. Tritium removal from either $\mathrm{He}$ or water is quite feasible.

A separate issue is whether secondary systems for tritium recovery are affordable. Thus far, we have used our limited resources in APEX primarily to investigate first the issues that tell us whether our design(s) are feasible based on fundamentals of science and engineering and the requirements imposed by integrating together the various technologies needed for our liquid wall chamber. The sizing and cost for a system compatible deployed as part of the balance of plant equipment needed to complement our liquid wall chamber design has not yet been done.

\section{Safety}

In this section we summarize the safety assessment performed for the Advance Ferritic Steel (AFS) Flinabe cooled blanket design in the APEX liquid wall chamber concept. A more detailed discussion can be found in a separate paper $^{15}$ in this journal. For this blanket design concept, we examine the site boundary dose during a worst-case (frequency $<10^{-6}$ per year) confinement-boundary-bypass accident. A confinementbypass accident was chosen because, based on a previous safety study [60], this accident can produce significant environmental releases. The worst-case confinement-bypass accident examined here is one that is postulated to occur as a result of a total loss-of-sitepower, which leads to a loss of plasma control and an induced plasma disruption. The electromagnetic currents generated in the internal components of the vacuum vessel (VV) by this disruption produces forces that in theory fail the windows of a diagnostic port or plasma-heating duct. In addition, the postulated rapid plasma current decay of this disruption produces runaway electrons that, when lost from the plasma confinement field, fail a blanket wall by melting. As a consequence, air from a room adjoining the reactor enters the plasma chamber by way of the failed VV port. This air reacts with the hot metal and spilt molten salt inside of the VV to mobilize radioactive material, and to transport this mobilized material to the adjoining room by natural convection airflow through the failed VV port. Because this room is a 'non-nuclear' room, that is a room that requires frequent human access for equipment maintenance and would not be leak tight, natural convection airflow to the environment can develop in a duct of the heatventilation-air conditioning (HVAC) system of this room. Of ultimate concern regarding this accident is the risk this accident poses to the public. Under the DOE Fusion Safety

\footnotetext{
${ }^{15}$ See "Safety Assessment of Two Ferritic Steel Molten salt Blanket Design Concepts" by B. Merrill et al. in this journal.
} 
Standard [61], the maximum allowed dose at the site should not exceed $10 \mathrm{mSv}$ during worst-case weather conditions [62]. This dose limit ensures that a site evacuation plan will not be required for a facility that adopts this blanket design concept.

The major radiological inventories in this blanket design are the activation products in the AFS structures, the activation products in the Flinabe coolant, and the tritium in blanket and cooling system components. These inventories can be mobilized during this accident scenario by AFS oxidation or coolant evaporation in the case of activation products, and by permeation in the case of tritium. Activation calculations were performed for the APEX liquid wall blanket design. The neutron flux used for the activation calculations was generated by the discrete ordinates neutron transport code DANTSYS 3.0 [63] The activation analysis was performed using the activation code DKR-PULSAR2.0 [64]. The code combined the neutron flux with the FENDL/A-2.0 [65] cross section library to calculate the activity and decay heat as a function of time following shutdown. The radioactive isotopes $\mathrm{Na}-22, \mathrm{Na}-24$, and F-18 dominate the radioactivity levels of the Flinabe of the APEX liquid wall blanket design. The dominant isotope in the AFS is Fe55. This blanket can be disposed of as Class C, or low-level waste.

We have used the Tritium Migration Analysis Program (TMAP) [66] to predict tritium permeation and inventories for this blanket concept. Three sources of tritium were considered: 1) tritium ions that escape the plasma magnetic field and impinge on the liquid first wall (FW), 2) tritium that is bred within the Flinabe coolant, and 3) tritium produced in the beryllium multiplier. The TMAP model developed for this blanket concept includes representations of the major reactor components of the primary heat transport system (PHTS). Based on our TMAP calculations, the total inventory of tritium in the NCF steel of the primary loop is about $115 \mathrm{~g}$. Of this inventory, the AFS in-vessel portion is $77.6 \mathrm{~g}$ ( $68 \%$ of total). Because of the very low solubility of tritium in Flinabe, there is less than 2 grams of tritium in the coolant.

Because the PHTS exists as four separate loops or quadrants, during this bypass accident, $1 / 4^{\text {th }}$ of the in-vessel components will experience a loss-of-cooling accident (LOCA) through the failed FW, while the remaining $3 / 4^{\text {th }}$ of the components will experience a loss-of-flow accident (LOFA) as pump power is lost. We use the MELCOR code $[67,68]$ to analyze the consequences of this accident. The input models for this blanket design include a complete one dimensional radial conduction/thermal-radiation heat transfer model of the in-vessel components and an entire PHTS. Based on MELCOR results, the APEX liquid wall blanket design does not produce high temperatures during a LOCA, but high temperatures $\left(\sim 1100^{\circ} \mathrm{C}\right)$ are reached for a sustained period of time during a LOFA due to the decay heat of Flinabe. Therefore, we are proposing that passive measures be taken to remedy this problem. Two possible measures are either an in-vessel natural convection decay heat removal system similar to those proposed by References $[69,70]$, or a passively activated valve that drains the Flinabe from the blanket into a tank that is passively cooled.

During a worst-case VV bypass accident, we determined that the release of AFS oxide aerosol, activated Flinabe aerosol, and tritium to the environment does not exceed the noevacuation dose limit of $10 \mathrm{mSv}$ during the first week of this accident, provided that these releases are stacked. Based on radiological dose calculations performed by Reference [71], the dose for stacked releases of tritium as HTO is $77 \mathrm{mSv} / \mathrm{kg}$, assuming a 1-km site 
boundary and worst-case weather conditions. The specific dose for the Flinabe is $1.1 \mathrm{mSv} / \mathrm{kg}$, with $91 \%$ of the dose from F-18, $7 \%$ of the dose from Na-22, and $2 \%$ of the dose from Na-24. Unlike the specific dose for tritium and the molten salts, the specific dose for the AFS will change with time because the oxide composition will vary with temperature. The specific dose for AFS oxides from the APEX liquid wall blanket starts at $8.3 \mathrm{mSv} / \mathrm{kg}$, peaks at $15.3 \mathrm{mSv} / \mathrm{kg}$ after one hour, and drops to $1.7 \mathrm{mSv} / \mathrm{kg}$ by seven days. The major contributors to the specific dose are Mn-54, Ca-45, and Ti-45. The dose at the site boundary is the integrated product of mass release times the specific dose. Based on these specific dose values and our predictions of radioactive AFS oxide, Flinabe aerosol, and tritium mass releases during this accident, the total dose at the site boundary after one week, if the releases are stacked, is $1.5 \mathrm{mSv}$. Given the rate of releases from the APEX liquid wall blanket design, the facility must be isolated within an additional two weeks to remain below the $10 \mathrm{mSv}$ limit. If these releases can not be stacked, then the facility would have to be isolated within five days. Even for ground releases, the time allowed for isolation and facility cleanup is adequate even for manual operation of plant remediation and isolation systems.

Safety analyses have been also performed as part of the development of liquid metal designs in APEX. These will not be summarized here but have been published elsewhere.[72]

\section{Power Conversion}

The APEX design activity has focused on the application of innovative technology for the fusion chamber. Our goal is to develop designs that would be appropriate for high power density fusion reactors. Our efforts do not cover other technology such as the magnets, power systems, reactor hall, etc., but there must clearly be some coupling to the energy conversion system. Our chosen "interface" is the primary heat exchanger.

For the Flinabe design, we have an operating temperature window with Flinabe from the blanket coming into the primary heat exchanger at $646^{\circ} \mathrm{C}$ and exiting at $312^{\circ} \mathrm{C}$, as shown in previous Figure 6. This is adequate for coupling to a steam cycle with reasonable efficiency in power conversion.

We also specify a secondary molten salt heat exchanger between the primary Flinabe loop and the steam generator. The need for the secondary heat exchanger arises primarily from concerns with tritium permeation from the primary Flinabe loop and the need for additional recovery of tritium to minimize the transport of tritium into the steam cycle.

\section{R\&D Issues}

The discussion of R\&D issues here is brief but extends beyond the specific APEX chamber design with Flinabe and includes the evolution of work in APEX. The major issues in developing designs for divertors as part of an integrated liquid chamber technology fall into the following categories:

- Plasma edge conditions and particle pumping

- Flow stability

- Piping, nozzles and auxiliary structures 
- Startup, shutdown, transients and safety

- Materials and fabrication

- Remote maintenance of the structure

There are also some inconsistencies that currently exist in our design calculations. These are note R\&D issues but simply work that has yet to be done. For example, the design choices to date have been based on average neutron wall loading and surface heat flux, shown previously in Table 2, being representative of the entire first wall area. In fact, the average neutron wall loading is significantly higher and the average surface heat flux slightly higher for the outboard first wall and blanket modules than for inboard wall and modules. This will not affect the design in a drastic way, but further analyses would yield a more accurate and detailed accounting of the power in inboard and outboard first wall and blanket modules and the flow rates in our figures and tables would have to be slightly modified.

Plasma edge conditions and particle pumping

For the ARIES/CLIFF design with free surfaces of flowing liquid Flinabe facing the plasma, a stable operating window for a plasma with high density and high recycling (very low throughput) was developed through detailed plasma edge modeling, as noted in Section 2.3). These results are very encouraging because they point toward a solution with relatively modest peak power onto the divertor.

The effort on plasma edge modeling identified several interesting issues on which further work should be done were resources available. One such area was pumping of helium ash and impurities. An often-used approach to pumping in tokamaks with high-density divertors and strong pumping is that sufficient helium will be carried with the hydrogen to provide reasonable exhaust of the (helium) ash and impurities. In many fusion plant designs, gas puffing of deuterium at the plasma edge is introduced for various reasons and dominates the exhaust stream, i.e., only a few percent of the exhaust stream is tritium. In the design presented here, there is no gas puffing, very high recycling, and very low throughput. The relatively low conventional pumping rate implied may not be sufficient to remove helium at its rate of production.

Another and perhaps related area is the effect of tilting of the target. In the UEDGE model discussed in Section 2.3, the target (divertor surface at the strike point) is orthogonal to the magnetic flux surfaces. Some modeling was also done in configurations with a tilted target (mostly before the strongly radiating solution was developed), and these results show some redistribution of the profiles of hydrogen and helium densities and temperatures along the divertor surface.

Adequate pumping of helium is a basic requirement for a fusion plant and is a critical issue if the conditions for pumping, e.g., high throughput exhaust, are not present. In the design here with a strongly radiation plasma edge, this solution has been developed without the need for strong gas puffing at the edge, which also would increase the throughput.

Productive directions for further edge modeling would be to investigate the effects of the tilting of the target and of increasing the throughput with gas puffing at the edge. 
However, implies a level of effort above that currently supported in the program. Each target angle requires a new mesh for the model. Also, the UEDGE cases for strongly radiating edge plasmas interacting with Flinabe walls have rather long run times, and developing each solution, after many non- converging trial runs, is a slow process.

The APEX effort included extensive edge modeling to address the issues of interaction between the plasma edge and the liquid surfaces. However the scope of work did not include a commensurate effort on modeling of a plasma core and coupling with the edge modeling. Two areas that might affect the edge solutions identified but could not be assessed during the work to date in the APEX and ALPS Programs are (1) the fueling scenario and the addition of cold hydrogen at the edge of the plasma and (2) access to the stable operating window from startup.

We also note here other researchers who are investigating the response of liquid surfaces as part of the ALPS and APEX Programs. This research has directly affected the design development reported here through our discussions in ALPS and APEX on the issues of implementing liquid chamber designs. Preparation for the installation of a Li test module in the NSTX (National Spherical Torus Experiment) has been reported by Ying and Ulrickson,[73] who c-chair an activity called ALIST on this research area. Ongoing experiments in CDX-U (Current Drive Experiment-Upgrade) that support the NSTX Limodule are a collaboration by the Princeton Plasma Physics Laboratory, the University of California, San Diego and others and have been reported by Kaita, Majeski and Doerner.[74,75] Some of this work was reported in the Mini-Conference on Lithium Walls and Low Recycling Regimes in Tokamaks I at the American Physical Society Meeting in Quebec City in 2000.[76]

\section{Fluid flow and stability}

The issues regarding flow stability differ somewhat for the low Prandtl ${ }^{16}$ number fluids (e.g., liquid metals) and high Prandtl number fluids (e.g., molten salts). The discussion below is divided into two parts.

For liquid metals (low Prandtl number), their thermal conductivity is so high that much of the heat transfer occurs through thermal conduction so that the effects of turbulence in heat transfer is diminished compared with other fluids. The primary general issue in the thermal-hydraulic control of liquid metal flows and in the design of free surface liquid metal flows for chamber technology is our current inability to predict the MHD effects. We must account for these in the development of chamber designs, and to do so, we will need 3-D models that can handle fast flow in high magnetic fields with field gradient effects and redirections of flow through bends and constrictions (nozzles) coupled with free surface flows. There is some development work in this area. However, the capability needed is beyond the current state-of the-art and represents a major challenge in engineering science. Another paper in this journal provides further discussion. ${ }^{17}$ An attractive aspect of liquid metal is the potential for the MHD effects to stabilize flow perturbations and suppress the formation of waves or splashing. This is particularly important for the divertor where a smooth surface is needed at the strike point. The

\footnotetext{
${ }^{16}$ The Prandtl number, $\operatorname{Pr}=\mathrm{C}_{\mathrm{p}} \square / \mathrm{k}$, where $\mathrm{C}_{\mathrm{p}}$, $\square$ and $\mathrm{k}$ are the heat capacity, viscosity and thermal conductivity.

${ }^{17}$ See "Modeling for liquid metal free surface MHD flow for fusion liquid walls" by N. Morley et al. in this journal.
} 
stabilization of flow in streams of liquid metals has been observed, but we cannot exploit such behavior in our designs until we extend our current understanding.

There are also other issues for the use of liquid metals for flowing first walls and divertors, such as the need for insulating layers and toroidal breaks in the first wall. These will become better defined as there is more progress on the understanding and prediction of fast MHD-controlled flows in high magnetic fields. If we do need to introduce insulating coatings on flow substrates, then there is also an important R\&D issue for materials development in this area. Another issue in this regard is the lack of data on basic physical properties of some liquid metals at temperature above the region near their melting point.

All of these are important issues and at the point where the implementation of liquid metal applications for fusion is considered, there must be serious consideration given to the coordinated effort in developing models and experiments and experimental facilities to address the needs for developing this technology.

For molten salts, turbulent heat transfer is extremely important. Controlling the quality of the surfaces of the flow streams is a fundamental issue for liquid chamber technology, and the requirements differ for the first wall and divertor streams.

Near the first wall, in the outer scrape off region, we anticipate comparatively little heat convected by charged particles, i.e., relatively small convected heat flux parallel to the magnetic field. This means that the first wall is not particularly sensitive to protrusions (bumps) that would intercept this parallel heat flux. Therefore waviness in the first wall flow stream is acceptable as long as the waviness does not lead to the generation of droplets that could move into the plasma.

In contrast, the divertor receives a high heat load from charged particles and its surface must be free of bumps or waviness that would cause a concentration of the heat load onto a small area unless the enhancement in thermal conduction from the wavy surface is enough to offset the very high heat local deposition. Thus far, we have looked briefly at this problem simply in terms of the increase in the intensity of the local heat flux.

For Flinabe, there is also a lack of consistent data on its physical properties. This issue is discussed later with materials $R \& D$ issues.

\section{Piping, nozzles and structure}

Our approach in specifying the piping and the nozzles that inject the flow for the first wall has been to develop what appears to be a reasonable arrangement based upon the considerations of space available within the envelopes consistent with the ARIES-RS design from which our configuration was taken. A clever design for the nozzle arrays was developed at Oak Ridge National Laboratory and plastic prototypes were even made using a rapid prototype fabrication process. However, the detailed fluid flow design for such nozzles has not been done.

The basic requirement is that the flow be free of drips, droplets and side spray and deliver a flow pattern that so that multiple streams will coalesce on the first wall without splashing and continue their momentum down the first wall so that a flow that is fairly uniform toroidally in its thickness and velocity is established. 
Confirming that a first wall flow system will perform as expected implies a detailed fluid flow analysis plus some type of testing program and associated facility. A related issue is the requirement for quality control in fabricating the nozzle arrays so that appropriate specifications for procuring arrays could be included in the detailed design.

Regarding fluid flow around penetrations, some initial design and analysis was done by Karani Gulec while at UCLA and a result was shown previously in Fig. 3. A sharp-edged solid chevron parts the fluid upstream of the penetration. Gulec studied fins and modifications to the shape of the back wall as methods to guide the flow. He found satisfactory initial results with gently sloped modifications to the shape of the back wall, such as recessing the back wall to increase the volume available for fluid adjacent to the penetration. Gulec provided for rejoining of the parted stream by beveling the lower part of the recess adjacent to the penetration to push fluid into the region downstream of the penetration. This technique worked but requires that the flow opening have a tapered tail.

We also propose, but have not yet analyzed, that additional flow be introduced from nozzles at the (poloidal) bottom of the cassette. This auxiliary stream would fill in the flow in the wake of the penetration and eliminate a tapered tail on the lower part of the cassette. Such an arrangement could reduce the overall height of the cassette and, in doing so, may also provide more flexibility in the arrangement of the hardware within the penetration. Since we would anticipate that some cooling would be needed for the structure within the cassette, the redirection of this cooling stream to become the fill flow in the wake of the penetration presents no new requirement in the technology beyond the design of the nozzles and flow streams. It is clear that more detailed design and fluid flow analysis are needed in the future, but we believe the analysis to date on the smooth parting flow around a large penetration and the joining flow below it indicate that the "penetration problem" can be managed.

We anticipate that some structure facing the plasma, such as some hardware for RF systems or possible the flow deflector in the divertor, may require internal cooling. For example, the preliminary thermal analysis of the flow deflector indicated that a design without internal cooling would only work if the lip of the deflector (a nominally unwetted leading edge to catch waves in the flow) was not too long. If a longer lip were needed (as might be shown by future analyses and experiments on the waviness of the first wall flow) then a more complicated design solution would be needed with auxiliary cooling by forced convection with a Flinabe stream in cooling channels inside the lip. This design is quite possible and would be accomplished by placing cooling channels in the deflector lip and connecting cooling passages in the body of the deflector and its support structure.

But such design work as well as the experiments and analysis on flows around penetrations remains as future work.

With the exception of the challenging problem of modeling liquid metal MHD effects in complicated geometries with high magnetic fields and flow rates, most of the issues noted above result from lack of information that can be addressed by future work as opposed to the need to find new solutions because of seemingly insurmountable problems. The scope of the work implies experimental and analytical efforts and new experimental facilities. 


\section{Startup, Shutdown, Transients and Safety}

There are several types of transients in the behavior of the plasma or the flowing layers of the liquid walls that can affect the performance of the facility. Most of these are poorly characterized at this time.

There are various issues associated with how the liquid flow is introduced and these have not yet been addressed. Preheating of the system to the temperatures needed to maintain the fluids as molten is an obvious requirement, but the provisions for this are not yet included in the design. For example, in our Flinabe design, we do not presently have start-up and shut-down scenarios that assure that the molten salt will remain in the liquid state to prevent plugging, or that plugging can be adequately mitigated to restore full operational capability.

We presume that the fluid must be present when the plasma startup occurs. For designs with liquid metal walls, magnetic transients during startup may present some concerns that need to be addressed.

A beneficial aspect of transients in the plasma behavior that produce hot spots in the flowing liquid is that the surface is continually regenerated and is therefore self repairing in this sense. This is true for plasma disruptions also. However, there is clearly the potential for consequences to the structure, such as the deflector in the divertor, that have not yet been analyzed.

For electrically conducting fluids, the coupling between motion of this fluid and motion and electrical currents in the plasma is receiving some study in the APEX and ALPS Programs, but this work is just starting. For liquid metals, the conducting shell near the plasma may have the potential for beneficial effects in stabilizing the plasma. However, the plasma coupled to a conducting shell with a free and movable surface is not a simple problem for analysis.

Transient events in the plasma that can lead to eddy currents in the auxiliary structure (e.g. plasma disruptions or rapid plasma displacements) may be mitigated in part by fluid walls in that a liquid metal wall would provide a huge conductance while a molten salt would insulate around auxiliary structures. However, neither the characteristics of such plasma events nor the response of the structures has been evaluated.

With regard to safety, a preliminary evaluation of the liquid metal chamber designs has been carried out, mainly from the point of view of accidents that could mobilize radiation and hazardous material. The accident analysis suggests that a loss-of-flow accident will produce excessive temperatures due to decay heat generated in Flinabe, and proposes either passive blanket cooling or passively activated blanket draining in certain accident scenarios. Passive cooling is not provided in the present design. Passive draining may be achievable with the present design, but further detailed investigation is needed.

Another issue related to tritium recovery and safety is the sizing and cost of a secondary system for tritium recovery in the balance of plant. As noted in the section on tritium processing, the molecular sieves and water distillation with vapor phase catalyst exchange are technically feasible methods. The sizing and cost of deploying such systems in a fusion reactor with flowing Flinabe chamber walls is an important task that still remains to be done. 


\section{Materials and fabrication}

We included here issues with regard to fluids as well as structural materials.

As we investigate the potential for liquid metals in detail, we will also need further data on the physical properties of such metals as tin, for which there is little data at temperatures much higher than their melting points.[77] We have used extrapolations of data in some cases, where little or no data existed.

For Flinabe in particular, our lack of data on its physical properties is a significant issue. For example, values between 240 and $315^{\circ} \mathrm{C}$ have been reported for its melting temperature. Our premise at this point is that there is a combination of lithium, beryllium and sodium fluorides with an acceptably low melting temperature to fit our desired window of operating temperature and that it will remain a homogeneous fluid through the temperature cycles of our reactor and its energy conversion system. Some R\&D is underway at the Idaho Engineering and Environmental Laboratory to make Flinabe and measure its melting temperature, but clearly more work will be needed to characterize the physical properties of this molten salt mixture and to observe and understand its behavior in a radiation environment so that the chemistry to mitigate the effects of radiationinduced breakup and ionization.

The primary structural material for the blanket specified in the design is ferritic steel with a nano-dispersion of oxide and is as yet unproven. Our material properties database is very limited. Among the concerns is the processing for production in large quantities. The current method of production involves thermo-mechanical treatments to obtain the super-fine dispersion of oxide. Currently, small lots of material are ball milled and vacuum-pressed under conditions of extremely good vacuum. Whether this, or other techniques for obtaining the beneficial microstructure, can be implemented for large production runs has not yet been determined. Also the material is not weldable. Diffusion bonding is the preferred joining technique and this becomes more difficult in complex geometries.

At this point we assume that the ultimate development of fusion as an energy source will require a purposeful parallel development of suitable materials. The high temperature performance of the material is driven by the desire for an operating window associated with high efficiency for electrical production. The potential for advanced ferritic alloys continues is recognized in the fusion program worldwide and there is ongoing research and development and much more is needed to confirm a material of this type for deployment in future fusion devices. A "first level" in this regard is that there are sufficient data to indicate that the basic performance requirements in terms of strength, creep resistance, corrosion, etc. are satisfied. While there are still issues, as noted above, the advanced ferritic steels do seem to have the capability provide the performance needed. A much more demanding level in the proving of materials must occur for the confirmation of performance needed to satisfy the projection of high, e.g., $97.8 \%{ }^{18}$, availability that will be required for the blanket system in a future fusion reactor. At that point, one needs detailed on a proven a proven material, which in turn implies significant materials development that includes the database itself plus a demonstrated capability to

\footnotetext{
${ }^{18}$ Goals for availability were presented in the APEX Interim report completed in January 2000. This document may be found on the APEX website http://www.fusion.ucla.edu/APEX/.
} 
produce and fabricate the material in conformance with the desired goals for performance and quality assurance.

\section{Remote maintenance of the structure}

Remote maintenance scenarios have been worked out at a superficial level. The modular design with replaceable cassettes, component lifetime assignments, component installation sequences, and component/sector removal scenarios are all partially driven by remote maintenance requirements. However detailed remote maintenance designs and maintenance scenarios have received little attention to date, leaving many important questions unanswered at this time.

\section{Closing Remarks and Acknowledgements}

In this paper we have presented a design for the components of a fusion reactor chamber in which jets of flowing molten Flinabe, a combination of lithium, beryllium and sodium fluorides, form the first wall and divertor, and Flinabe is also the breeding material in the blanket. We have also presented some work on other concepts to show the overall scope of the effort.

That a design could be developed with a molten salt, with its low thermal conductivity, as the primary heat transfer agent, is a surprising and, we believe, significant result. An important aspect of this result was the determination of an acceptable power balance, confirmed through extensive plasma edge modeling, in which the power load to the divertor was limited through radiation from the plasma core and plasma edge.

In our approach to design for an advance chamber technology with liquid walls, we are assuming that various technologies can be made available in the future. We believe our technological solutions are "reasonable extrapolations" with a basis for their feasibility in current science and technology. Our intent is to show new potential directions for fusion chamber technology that can help guide the vision for fusion and the directions for research in both technology and physics.

The work is the result of effort by the APEX Team. The work of two authors (TDR and MER) was performed under the auspices of the U.S. Department of Energy by contractW-7405-Eng-48 at the University of California Lawrence Livermore National Laboratory. The primary contributors are listed as authors but the design effort has been presented in APEX Meetings with helpful discussions by the entire APEX Team and the Director of APEX, Prof. Mohamed Abdou. The APEX Team and more information about the APEX Study is given on the APEX website http://www.fusion.ucla.edu/APEX/. The authors also wish to express their appreciation to the Office of Fusion Energy Science of the Department of Energy and to the DOE Manager of the APEX Study, Sam Berk for supporting this work.

\section{References}

[1] M.A. Abdou, the APEX Team, Exploring novel high power concepts for attractive fusion systems, Fus. Eng. \& Des. 45 (1999) 145-167; see also APEX website http://www.fusion.ucla.edu/APEX/ 
[2] R. Mattas and ALPS Team, ALPS - Advanced Limiter-Divertor Plasma Facing Systems,Fus. Eng. \& Des. 49-50 (2000) 127; see also the ALPS website $<$ http://fusion.anl.gov/ALPS_Info_Center/calls.html $>$

[3] B. Badger, UWMAK-I, A Wisconsin Toroidal Fusion Reactor Design, University of Wisconsin, UWFDM-68 (1973)

[4] L. Golubchikov, Development of a Liquid-Metal Fusion-Reactor Divertor with a Capillary-Pore System, JNM, 237 (1976) 667-672

[5] J.H. Pitts, A Consistent HYLIFE Wall Design that Withstands Transient Loading Conditions, 4th ANS Topical Mtg. On the Technology of Controlled Nuclear Fusion, King of Prussia, PA, Oct. 14-17, 1980

[6] E. Muraviev, Contact Devices for Divertor and Limiter Systems of Tokamak Reactors. I. Devices with LM Working Surface, Voprosy Atomnoi Nauki I Tekhniki, Ser. Termoyaderniy Sintez, 2, (1980) 57-64

[7] W. Wells, A System For Handling Divertor Ion and Energy Flux Based on a Lithium Droplet Cloud, Nuclear Technology/Fusion 1 (1981) 120

[8] V. Baranov, Liquid Metal Film Flow for Fusion Application, 7th Beer Sheva International Seminar on Liquid Metal Magnetohydrodynamics, 1983

[9] A. Bond, A Liquid Metal Protected Divertor for a Demo Reactor, 13th Symposium on Fusion Technology, Varese, Italy, (1984) 1225

[10] B. Karasev, LM Contact Divertor for INTOR Tokamak Reactor, 4th All-Union Conf. on Engineering Problems of Fusion Reactors, Leningrad, (1988) 225-256

[11] V. Vodyanyuk, 'Liquid Metal Tokamak Limiter - Problem Definition and First Results, Plasma Physics, 14, (1988) 628

[12] I. Kirillov, Alternate Concepts of the Divertor Targets Working Materials to the ITER, October 1990, ITER-IL-PC-8-0-18

[13] C. Liao, A Feasibility Assessment of Liquid-Metal Divertors, Fusion Technology, 21, (1992) 1845-1851

[14] S. Mirnov, Liquid-Metal Tokamak Divertors, JNM 196 (1992) 45-49

[15] V. Chuyanov, Advanced Divertor Plates System Development Proposal, ITER EDA Memo (1994)

[16] E. Muraviev, Liquid-Metal-Cooled Divertor for ARIES, Fusion Engineering and Design, 29 (1995) 98-104

[17] E. Muraviev, Open Surface MHD Flow of Liquid Metal Coolant in a Rotating Divertor Target of a Tokamak Fusion Reactor, Magnetohydrodynamics, 31 (1995) 306

[18] V. Pistunovich, "Research of the Capillary Structure Heat Removal Efficiency Under Divertor Conditions, JNM 237 (1996) 650-654

[19] V. Lazarev et al., Compatibility of the lithium capillary limiter with plasma in T11M, ECA 23J (1999), 845-848

[20] V.A. Evtikhin et al., Energy removal and MHD performance of lithium capillarypore systems for divertor target application, FED 49 (2000) 195-199

[21] M.A. Mahdavi, M. Schaffer, Heat Removal with a Liquid Pellet Curtain (paper), Innovative Confinement Concepts Workshop held at Princeton Plasma Physics Laboratory (April 1998). 
[22] J. Sheffield, World population and energy demand growth: the potential role of nuclear energy in an efficient world, Fusion Tech., 34, 3 Pt.2, (1998) p281-287; see also, World population and energy demand growth: the potential role of fusion energy in an efficient world, Phil. Trans. of the Royal Soc. Of London, Series A Math. Phys. \& Eng. Sci., 357 \#1752 (Mar 1999) 377-391

[23] J. Sheffield, K.A. Williams, R.L. Reid, S. Hadley, An assessment of the economics of future electric power generation options and the implications for fusion, Fus. Tech., 39 \#2 (Mar 2001) 228-248

[24] M.A. Tillack et al., Engineering Design of the ARIES-RS Power Plant, Fus. Eng. \& Des. 41 (1998) 491; also http://aries.ucsd.edu/PUBLIC/ariesrs.html

[25] C.P.C Wong, et al., ARIES Divertor System - Selection and Analysis, FED 38 (1997) 115

[26] T.D. Rognlien and M.E. Rensink, Edge-plasma properties in liquid-wall environments, 8th Int. Workshop on Edge Plasma Theory in Fusion Devices, Helsinki, Finland, Sept. 10-12, 2001

[27] B.J. Merrill, D.K. Sze, H.Y. Khater, E.A. Mogahed, Safety implications of CliFF liquid metal first walls, FED 63-64 (2002) 285-293

[28] T.D. Rognlien, M.E. Rensink, Interactions between liquid-wall vapor and edge plasmas, JNM 290-293 (2001) 312-316

[29] R. Bastasz and W. Eckstein, Plasma-Surface Interactions on Liquids, JNM 290-293 (2001) 19-24

[30] J.N. Brooks, T.D. Rognlien, D.N. Ruzic and J.P. Allain, Erosion/redeposition of lithium-based liquid surface divertors, JNM. 290-293 (2001) 185

[31] S.Smolentsev, B.Freeze, N.Morley, M.Abdou, Experimental study of turbulent supercritical open channel water flow as applied to the CLiFF concept, Fusion Eng. $\&$ Design, to be published

[32] B.Freeze, S.Smolentsev, N.Morley, M.Abdou, Characterization of surface waves and their effect on heat transfer in high Fr, high We open channel turbulent water flow, Int. J. Heat \& Mass Transfer, to be published

[33]S.Smolentsev, M.Abdou, N.Morley, A.Ying, T.Kunugi, Application of the K-epsilon model to open channel flows in a magnetic field, International Journal of Engineering Science 40 (2002) 693-711

[34] J.N. Brooks, D. Naujoks, Sheath superheat transmission due to redeposition of thermally emitted material, Physics of Plasmas 7 (2000) 2565

[35] Naujoks, J.N. Brooks, Combined sheath and thermal analysis of overheated surfaces in fusion devices, JNM 290-293(2001) 1123

[36] J.N. Brooks, Modeling of sputtering erosion/redeposition - status and implications for fusion design, FED, 60 \#4 (July 2002) p515-526

[37] H.Ueda, R.Moller, S.Komori, T.Mizushina, Eddy diffusivity near the free surface of open channel flow, Int. J. Heat Mass Transfer 20 (1977) 1127

[38] J.H. Schaffer, Preparation and handling of salt mixtures for the molten salt reactor experiments, Oak Ridge National Laboratory, Oak Ridge, Tenn., (1971) ORNL$4616(1971)$ 
[39] S. Cantor, Density and Viscosity of Several Molten Flouride Mixtures, Oak Ridge National Laboratory, Oak Ridge, Tenn., (1973) ORNL/TM-4308; see also S. Cantor et al., Viscosity and Density in LiF-BeF2 Solutions, J. Chem. Phys., 50 (1969) 2874

[40] S. Cantor, S.D.S. Hsu, W.T. Ward, Vapor Pressures of Flouride Melts, in Reactor Chem. Div. Annual Progress Report, Oak Ridge National Laboratory, Oak Ridge, Tenn., (1965) ORNL-3913 24-26

[41] R.W. Moir, M.G. Adamson, R.O. Bangerter, R.L. Bieri, R.H. Condit, et al., HYLIFE Progress Report, Lawrence Livermore National Laboratory, Livermore, CA (1991) UCID-21816; see also R.W. Moir et al., HYLIFE-II: A Molten-Salt Inertial Fusion Energy Power Plant Design--Final Report, Fusion Technology 25 (1994) 5-25.

[42] D.L. Smith, et al., Blanket Comparison and Selection Study (final report), Argonne National Laboratory, Argonne, IL (Sept. 1984) ANL-Report, ANL:FPP-84-1. vols. 1-3; see also D.L. Smith, C.C. Baker, D.K. Morgan, M.A. Abdou, et al., Overview of the Blanket Comparison and Selection Study, Fusion Tech. 8,1 (1985) 10-44

[43] N.A. Toropov, I.L. Shchetnikova, Modelnye Sistemy - Na2BeF4-Li2BeF4 I Ca2SiO4-Mg2SiO4, Zhurnal Neorganische Khimi 2,8 (1957) 1855-1863

[44] W. R. Grimmes et al, Fused-salt Systems, Sec. 6 in Reactor Handbook, Vol. 2, Engineering, USAEC Report AECD-3646, 1955

[45] D.K. Sze, K. McCarthy, M. Sawan, M. Tillack, A. Ying, S. Zinkle, Flibe assessments, Fusion Tech. 2,2 (2001) 746-752

[45] Muroga, T; Gasparotto, M; Zinkle, SJ, Overview of materials research for fusion reactors, FED 61-62 (2002) 13-25

[46] S. Zinkle and N. Ghoniem, Operating Temperature Windows for Fusion Reactor Structural Materials, Fusion Eng. \& Design, 51-52 (2000) 55-71

[47] R. L. Klueh, et al. Microstructure and Mechanical Properties of Oxide DispersionStrengthened Steels, DOE/ER-0313/28, June 2000; see also R.L. Klueh, P.J. Maziasz, I.S. Kim, L. Heatherly, D.T. Hoelzer, N. Hashimoto, E.A. Kenik and K. Miyahara, Tensile and Creep Properties of an Oxide Dispersion-Strengthened Ferritic Steel, Journal of Nuclear Materials 307-311 (2002) 773-777.

[48] S. Ukai and M. Fujiwara, Perspective of ODS Alloys Application in Nuclear Environments, Journal of Nuclear Materials, 307-311 (2002) 749-757.

[49] D.L. Smith, J.H. Park, I. Lyubinski, V. Evitkhin, A. Perujo, H. Glassbrenner, T. Terai, S. Zinkle, Progress in coating development for fusion systems, FED 61-62 (2002) 629-641

[50] M.Z. Youssef, N.B. Morley, and D-K Sze, Nuclear Performance of the Thin-Liquid FW Concept of the CLiFF Design, Fusion Technology, 39 2,2 (2001) 839-845.

[51] M.Z. Youssef, M.E. Sawan, and D.-K. Sze, The breeding Potential of Flinabe and Comparison to Flibe in CLiFF High Power Density Concept, Fusion Engr.\& Design, 61-62 (2002) 497-503.

[52] M.Z. Youssef, M.S. Sawan, Component Lifetime Comparison and Waste Volume In CLiFF Sn/Flibe and Sn/LiPb Blankets, this issue, Fusion Eng. \& Design, 63-64 (2002) 277-283.

[53] M.Z. Youssef and M.A. Abdou, Heat Deposition, Damage, and Tritium Breeding Characteristics in Thick Liquid Wall Blanket Concepts, Fusion Eng. \& Design, 4950, 2000, 719. 
[54] M.Z. Youssef and M.S. Sawan, Radwaste Volume In Lithium And Flibe LW And Comparison To Conventional SW Concepts, Fusion Eng.\& Design, 63-64 (2002) 263-269.

[55] W. W. Engle, ANISN: A One Dimensional Discrete Ordinates Transport Code with Anisotropic Scattering, Report K-1693, Union Carbide Corporation, 1967.

[56] A.B. Pashchenko, Completion of FENDL-1 and Start of FENDL-2, INDC(NDS)352, IAEA Nuclear Data Section, International Atomic Energy Agency, March 1996.

[57] F. Najmabadi, et al., Overview of the ARIES-RS Reversed-Shear Tokamak Power Plant Study, Fusion Engr. \& Design, 38 (1997) 3-35.

[58] M.Z. Youssef, N. Morley, A. El-Azab, X-Ray Surface and Volumetric Heat Deposition and Tritium Breeding Issues in Liquid-Protected FW in High Power Density Devices, Fusion Technology 34 (1998) 697-705.

[59] A. P. Malinauskas and D.M. Richardson, MSR Program Semiannual Progress Report, Oak ridge National Laboratory, Oak Ridge, TN (Feb. 1972) ORNL-4782

[60] R. Aymar, et al., Technical Basis for the ITER Final Design Report, Cost Review and Safety Analysis (FDR), ITER EDA Documentation Series No. 16, International Atomic Energy Agency, Vienna, 1998, chapter IV, 36-50.

[61] DOE STD 6002-96, The Safety of Magnetic Fusion Facilities: Requirements, May 1996.

[62] L. Cadwallader, D. Petti, Safety in the Design of Three Burning Plasma Experiments, presented at the 15th Topical Meeting on the Technology of Fusion Energy, Washington, DC, November 17-21, 2002, to be published in Fusion Science and Technology.

[63] R.E. Alcouffe et al., DANTSYS 3.0, One-, Two-, and Three-Dimensional Multigroup Discrete Ordinates Transport Code System, RSICC Computer Code Collection CCC-547, Contributed by Los Alamos National Lab, August 1995.

[64] M. J. Sisolak, Q. Wang, H. Khater and D. Henderson, DKR-PULSAR2.0: A Radioactivity Calculation Code that Includes Pulsed/Intermittent Operation, in press.

[65] A. Pashchenko et al., FENDL/A-2.0: Neutron Activation Cross-Section Data Library for Fusion Applications, Report INDC(NDS)-173, IAEA Nuclear Data Section, March 1997

[66] B. J. Merrill, J. L. Jones, D. F. Holland, TMAP/MOD1: Tritium migration analysis program code description and user's manual, Idaho National Engineering Laboratory Report, EGG-EP-7407 (April 1988).

[67] R. O. Gauntt, et al., MELCOR Computer Code Reference Manuals: Version 1.8.4, NUREG/CR-6619, Vol. 2, Rev. 1, July 1997, HS-RM 37-41.

[68] B. J. Merrill, R. L. Moore, S. T. Polkinghorne, D. A. Petti, Modifications to the MELCOR code for application in fusion accident analysis, Fusion Engineering and Design, 51-52 (2000) 555-563.

[69] C. P. C. WONG, et al, Evaluation of the Tungsten Alloy Vaporizing Lithium First Wall and Blanket Concept, Fusion Technology 39 (2001) 815-822. 
[70] D. Steiner, et al., ARIES-RS safety design and analysis, Fusion Engineering and Design 38 (1997) 189-218.

[71] M. Abbott, Revised Results - MACCS2 Doses for Fusion Isotopes Released to the Atmosphere using P-G Dispersion Parameters, an INEEL letter to D. A. Petti, MLA-11-99, April 14, 1999.

[72] B.J. Merrill, D.K. Sze, H.Y. Khater, E.A. Mogahed, Safety implications of CLiFF liquid metal first walls, FED 63-64 (2002) 285-293

[73] A. Ying et al., MHD and Heat Transfer Issues and Characteristics for Li Free Surface Flows under NSTX Conditions, $14^{\text {th }}$ ANS Topical Meeting on the Technology of Fusion Energy, Oct. 15-19, 2000 Park City, Utah

[74] R. Kaita, R. Majeski, M. Boaz, P. Efthimion, B. Jones, et. al., Spherical torus plasma interactions with large-area liquid lithium surfaces in CDX-U, Fus. Eng. \& Des., 61-62 (2002) 217-222

[75] R. Majeski, M. Boaz, D. Hoffman, B. Jones, R. Kaita et. al., CDX-U operation with a large area liquid lithium limiter, J. Nucl. Mat. 313 (Mar 2003).625-629

[76] see conference website, http://www.aps.org/meet/DPP00/baps/abs/S1350.html

[77] R.E. Nygren, Part 4, Section 7 "Notes on the thermal Properties of Sn," in ALPS Report (August 2001) 162, see http://fusion.anl.gov/ALPS_Info_Center/alps.pdf 
Table 1. Power balance parameters for the APEX chamber systems

$\begin{array}{lc}\text { First wall area } & 434 \mathrm{~m}^{2} \\ \text { Average neutron wall loading } & 7.08 \mathrm{MW} / \mathrm{m}^{2} \\ \text { Average surface heat flux } & 1.76 \mathrm{MW} / \mathrm{m}^{2} \\ \text { Fusion power } & 3840 \mathrm{MW} \\ \text { Alpha power } & 767 \mathrm{MW} \\ \text { Auxiliary power to plasma } & 142 \mathrm{MW} \\ \text { Power to the first wall } & 765 \mathrm{MW} \\ \text { Power to the divertor } & 144 \mathrm{MW} \\ \text { Neutron power } & 3073 \mathrm{MW} \\ \text { Blanket energy multiplication } & 1.06 \mathrm{MW} \\ \text { Blanket thermal power } & 3257 \mathrm{MW} \\ \text { Total thermal power } & 4024 \mathrm{MW} \\ \text { Total power (thermal + aux.) } & 4166 \mathrm{MW}\end{array}$

Table 2. Heat loads and coolant flow in the first wall (FW) and divertor

Neutron wall loading, average

Neutron wall loading, maximum

FW surface heat flux, average

FW surface heat flux, maximum

FW surface heat load

FW nuclear heating

Total power removed by $\mathrm{FW}$

Power removed by divertor

FW maximum surface temperature

FW inlet temperature

FW exit temperature

Divertor exit temperature

Coolant flow rate

Coolant flow rate to blanket

Recirculation coolant flow rate

$\begin{array}{rl}7 & \mathrm{MW} / \mathrm{m}^{2} \\ 10 & \mathrm{MW} / \mathrm{m}^{2} \\ 1.76 & \mathrm{MW} / \mathrm{m}^{2} \\ 3.5 & \mathrm{MW} / \mathrm{m}^{2} \\ 765 & \mathrm{MW} \\ 400 & \mathrm{MW} \\ 1165 & \mathrm{MW} \\ 144 & \mathrm{MW} \\ 510 & \mathrm{C} \\ 402 & \mathrm{C} \\ 420 & \mathrm{C} \\ 422 & \mathrm{C} \\ 27000 & \mathrm{Kg} / \mathrm{s} \\ 5100 & \mathrm{Kg} / \mathrm{s} \\ 21900 & \mathrm{Kg} / \mathrm{s}\end{array}$


Table 3. Heat loads and coolant flow in the blanket

$\begin{array}{lll}\text { Blanket power } & 2857 & \mathrm{MW} \\ \text { Blanket coolant inlet temperature } & 422 & \mathrm{C} \\ \text { Coolant temperature entering the Be bed } & 483 & \mathrm{C} \\ \text { Coolant temperature exiting the Be bed } & 544 & \mathrm{C} \\ \text { Maximum Be temperature } & 600 & \mathrm{C} \\ \text { Blanket exit temperature } & 646 & \mathrm{C} \\ \text { Coolant temperature entering the HX } & 646 & \mathrm{C} \\ \text { Return coolant temperature from the HX } & 312 & \mathrm{C} \\ \text { Blanket flow rate } & 5100 & \mathrm{Kg} / \mathrm{s} \\ \text { Estimated power conversion efficiency } & 49 \% & \\ \text { Width of the blanket unit } & 300 & \mathrm{~mm} \\ \text { Width of the side wall channel } & 10 & \mathrm{~mm} \\ \text { Diameter of the Be pebble } & 5 & \mathrm{~mm} \\ \text { Radial depth of the Be bed } & 60 & \mathrm{~mm} \\ \text { Coolant velocity along the side channel } & 0.18 & \mathrm{~m} / \mathrm{s} \\ \text { Coolant velocity in blanket module } & 0.013 & \mathrm{~m} / \mathrm{s} \\ \text { Pressure drop through Be bed } & 0.02 & \mathrm{MPa} \\ \text { Other pressure drops } & \mathrm{small} & \end{array}$

Table 4. Chamber Modules

\begin{tabular}{|c|c|c|c|}
\hline module type & Volume $\left(\mathrm{m}^{3}\right)$ & \#/sector & tota \\
\hline inboard blanket & 3.11 & 3 & 48 \\
\hline outboard blanket & & & \\
\hline full length modules & 3.77 & 3 & 48 \\
\hline penetration modules & 2.46 & 2 & 32 \\
\hline nozzle cassette & 9.50 & 1 & 16 \\
\hline divertor cassette & 2.95 & 1 & 16 \\
\hline main shield module & 26.22 & 1 & 16 \\
\hline removable rear plug, top & 7.54 & 1 & 16 \\
\hline removable rear plug, middle & 2.95 & 1 & 16 \\
\hline removable rear plug, bottom & 8.19 & 1 & 16 \\
\hline RF system cassette & 1.23 & 1 & 16 \\
\hline Diagnostic cassette & 1.23 & 1 & 16 \\
\hline
\end{tabular}




\section{Table 5. RF Heating for ARIES-RS/CLIFF}

type function freq. power density power width height location

$\begin{array}{lcccccl} & (\mathrm{Hz}) & (\mathrm{MW}) & (\mathrm{MW}) & (\mathrm{m}) & (\mathrm{m}) & \\ \text { ECH core current drive } & & 100 & 80 & 0.15 & 0.17 & 2 \text { per sector } \\ \text { LH edge overdrive } & 4.6 \mathrm{G} & 88 & 12 & 0.35 & 0.39 & \text { one only }\end{array}$

Table 6. Piping Specifications

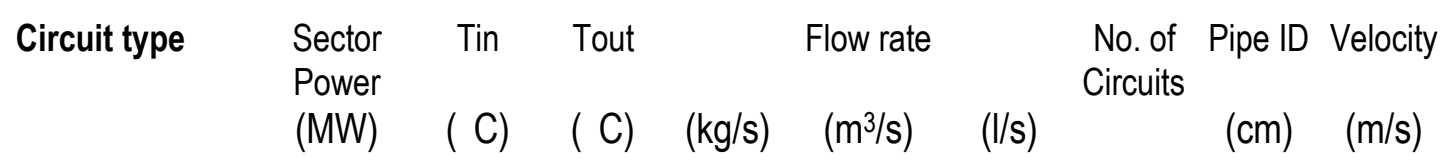

\section{First wall fast flow}

Inboard

Outboard

Flow under OB

penetration

Total, all sectors 1165

Blanket modules

Inboard

Outboard

Total, all sectors $\quad 2808$ $\begin{array}{lll}28.6 & 403 & 420\end{array}$

$\begin{array}{lll}41.2 & 403 & 420\end{array}$

$3.0 \quad 403 \quad 420$

$\begin{array}{rrrrr}663 & 0.331 & 331 & 10 & 15 \\ 955 & 0.478 & 478 & 20 & 15 \\ 70 & 0.035 & 35 & 21 & 3.5\end{array}$

$\begin{array}{lllll}70 & 0.035 & 35 & 21 & 3.5\end{array}$

$15 \quad 1.9$

$\begin{array}{ll}5 & 1.4\end{array}$

$3.5 \quad 1.7$

\section{Divertors}

Inboard

$\begin{array}{lll}3.2 & 420 & 422\end{array}$

Outboard

Total, all sectors

$5.8 \quad 420 \quad 422$ Cooled by first wall fast flow 144

Structure (Shielding, Vacuum Vessel, etc.)

Inboard

Outboard

2.0

422

437

437

$27000 \quad 13.5 \quad 13500$

Total, all sectors

49

49

$\begin{array}{rlrlll}54 & 0.027 & 27 & 4 & 7.5 & 1.5 \\ 29 & 0.014 & 14 & 4 & 5 & 1.8 \\ 1316 & 0.66 & 658 & & & \end{array}$


TABLE 7

RADiAl BuILD AT THE MidPlane OF THE INITIAL APEX LW CONFIGURATION

\begin{tabular}{|c|c|c|c|}
\hline \multicolumn{2}{|l|}{ Inboard Side } & \multicolumn{2}{|l|}{ Outboard Side } \\
\hline Zone & $\begin{array}{l}\text { Inner Radius } \\
(\mathrm{cm})\end{array}$ & Zone & $\begin{array}{c}\text { Inner Radius } \\
(\mathrm{cm})\end{array}$ \\
\hline Central Solenoid & 13.6 & Plasma & 437 \\
\hline Inner Casing $^{1}$ & 91.7 & SOL & 687 \\
\hline Winding Pack ${ }^{9}$ & 101.8 & Liquid FW ${ }^{8}$ & 690 \\
\hline Outer casing $^{1}$ & 199.88 & FW substrate $^{7}$ & 692 \\
\hline Gap & 209 & Blanket $^{6}$ & 692.5 \\
\hline V.V. Inner Wall ${ }^{2}$ & 289 & HT- Shield ${ }^{5}$ & 752.5 \\
\hline V.V. ${ }^{3}$ & 291 & Gap & 782.5 \\
\hline V.V. Outer Wall ${ }^{2}$ & 307 & LT-Shield $^{4}$ & 784.5 \\
\hline Gap & 309 & Gap & 814.5 \\
\hline LT-Shield $^{4}$ & 314 & V.V. Inner Wall ${ }^{2}$ & 825 \\
\hline Gap & 342 & V.V. $^{3}$ & 827 \\
\hline HT- Shield ${ }^{5}$ & 344 & V.V. Outer Wall ${ }^{2}$ & 853 \\
\hline Blanket $^{6}$ & 371.5 & Gap & 855 \\
\hline FW substrate $^{7}$ & 411.5 & Inner Casing $^{1}$ & 875 \\
\hline Liquid $\mathrm{FW}^{8}$ & 412 & Winding Pack ${ }^{9}$ & 893 \\
\hline SOL & 414 & Outer Casing $^{1}$ & 992.5 \\
\hline Outer Radius & & & 1012.5 \\
\hline
\end{tabular}

(1) $100 \%$ SS316 LN (2) $100 \%$ Ferritic Steel (3) $81 \%$ SS316, $19 \%$ water (4) Low-Temperature shield: 95\% Structure, 5\% Coolant/Breeder (5) High-Temperature shield: 95\% Structure, 5\% Coolant/Breeder (6) 90\% Breeder/Coolant, 10\% Structure. When a multiplier is used, the first 10 $\mathrm{cm}$ consists of $60 \%$ Be, $30 \%$ breeder, and 10\% Structure (7) 100\% Structure (8) Liquid Breeder (9) 18\% epoxy, 19\% Cu, 3\% $\mathrm{Nb}-\mathrm{Sn}, 17 \%$ Liquid He-4, 43\% SS316 LW

TABle 8: The ReQuired [ $\square(B e)$ ] And EfFective, [ $\square_{e}(B e)$ ] Thickness OF THE BERYLLIUM ZONE TO ACHIEVE LOCAL TBR OF 1.4

\begin{tabular}{|l|c|c|c|c|}
\hline \multirow{2}{*}{ Structure Type } & \multicolumn{2}{|c|}{ Flibe } & \multicolumn{2}{c|}{ Flinabe } \\
\cline { 2 - 5 } & $\square(B e)$ & $\square_{e}(B e)$ & $\square(B e)$ & $\square_{e}(B e)$ \\
\hline Ferritic Steel & $\sim 5.5$ & $\sim 3.3$ & $\sim 9.5$ & $\sim 5.7$ \\
\hline SiC & $\sim 6.5$ & $\sim 3.9$ & $\sim 10.5$ & $\sim 6.3$ \\
\hline
\end{tabular}


Table 9: Total Power and Power Multi0lication in APEX LW CONCEPT

$\left(\right.$ Average NeUtron WALl LOAD $=7 \mathrm{MW} / \mathrm{M}^{2}$ )

\begin{tabular}{|l|c|c|}
\hline & Latest LW & Initial LW \\
\hline Total Nuclear Power Deposited per cm Height, MW/cm & 5.15 & 5.62 \\
\hline Total Incident Power per cm Height, MW/cm & 4.86 & 4.86 \\
\hline Power Multiplication (PM) & $\sim \mathbf{1 . 0 6}$ & $\sim \mathbf{1 . 1 6}$ \\
\hline
\end{tabular}

Table 10: Percentage (\%) Power Deposited in Various Components*

\begin{tabular}{|l|c|c|}
\hline Component & $\mathrm{I} / \mathrm{B}$ & $\mathrm{O} / \mathrm{B}$ \\
\hline Front Flinabe Liquid layer & $\mathbf{1 3 . 7 4 \%}$ & $\mathbf{1 2 . 2 7 \%}$ \\
\hline Blanket: & $3.69 \%$ & $3.56 \%$ \\
- Solid 1 & \\
- Ft Wall & $21.37 \%$ & $20.14 \%$ \\
- Beryllium Zone & $22.82 \%$ & $23.43 \%$ \\
- Back Breeding Zone & $35.25 \%$ & $39.85 \%$ \\
Subtotal: & $\mathbf{8 3 . 1 3 \%}$ & $\mathbf{8 6 . 9 8} \%$ \\
\hline Shield & $\mathbf{3 . 0 9 \%}$ & $\mathbf{0 . 7 4 \%}$ \\
\hline Vacuum Vessel & $\mathbf{0 . 0 4 \%}$ & $\mathbf{0 . 0 1 \%}$ \\
\hline Total & $\mathbf{1 0 0 \%}$ & $\mathbf{1 0 0 \%}$ \\
\hline
\end{tabular}

- $\quad \%$ of Total Nuclear Heating Rate : Inboard $\sim 31.13 \%$, Outboard $\sim 68.87 \%$

TABLE 11: Minimum SHIELD THICKNESS REQUIREMENT IN APEX LW CONCEPT FOR RADIATION DAMAGE NOT TO EXCEED DESIGN LIMITS

\begin{tabular}{|l|c|c|}
\hline & $\begin{array}{c}\text { Inboard } \\
(\mathbf{c m})\end{array}$ & $\begin{array}{c}\text { Outboard } \\
(\mathbf{c m})\end{array}$ \\
\hline $\begin{array}{l}\text { Fast Neutron Fluence (En>0.1 MeV) } \\
\text { Design Limit: } \mathbf{1} \boldsymbol{x} \mathbf{1 0}^{\mathbf{1 9}} \mathbf{n} / \mathbf{c m} \mathbf{2}\end{array}$ & $\mathbf{5 6}$ & $\mathbf{2 6}$ \\
\hline $\begin{array}{l}\text { Dose to Insulator, Rads } \\
\text { Design Limit: } 1.0 \times 10^{11} \mathrm{rads}\end{array}$ & 48 & 12 \\
\hline $\begin{array}{l}\text { Cu Stabilizer, dpa } \\
\text { Design Limit: } 6 \times 10-3 \mathrm{dpa}\end{array}$ & 54 & 23 \\
\hline $\begin{array}{l}\text { Vacuum Vessel, dpa } \\
\text { Design Limit: } 200 \mathrm{dpa}\end{array}$ & $\begin{array}{l}\text { No } \\
\text { restriction }\end{array}$ & $\begin{array}{l}\text { No } \\
\text { restriction }\end{array}$ \\
\hline $\begin{array}{l}\text { Vacuum Vessel Helium, appm } \\
\text { Design Limit: } 1 \text { appm }\end{array}$ & 37 & 25 \\
\hline
\end{tabular}


Figures 1-12 for FED Special Issue Paper: Nygren et al., A Fusion Reactor Design with a Liquid First Wall and Divertor
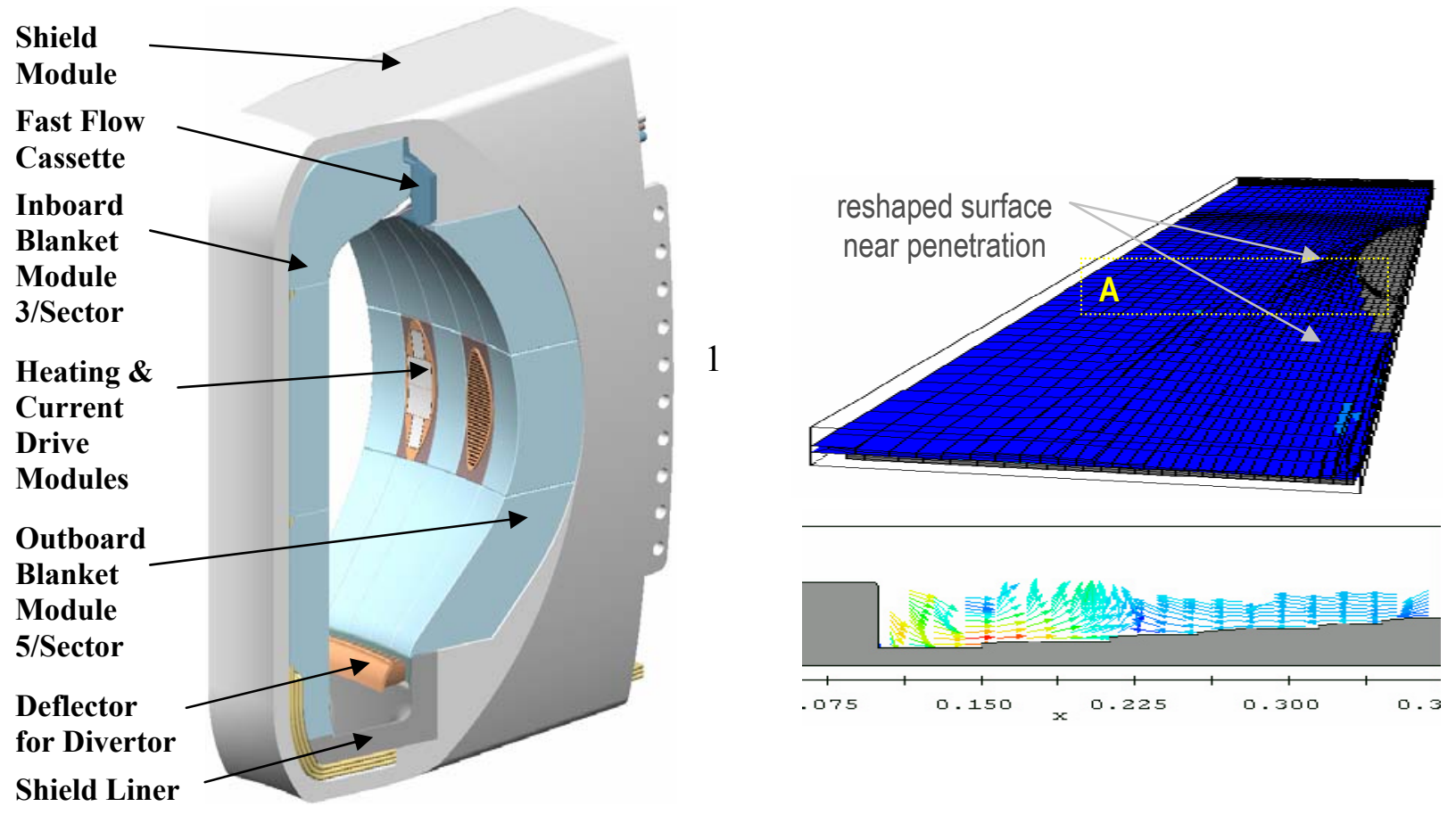

Figure 1. Chamber components: first wall and divertor, blanket and shield

Figure 3. Flow around a penetration: modified wall topology (top); flow cross section (lefthanded view) at A showing velocity vectors perpendicular to downstream direction.

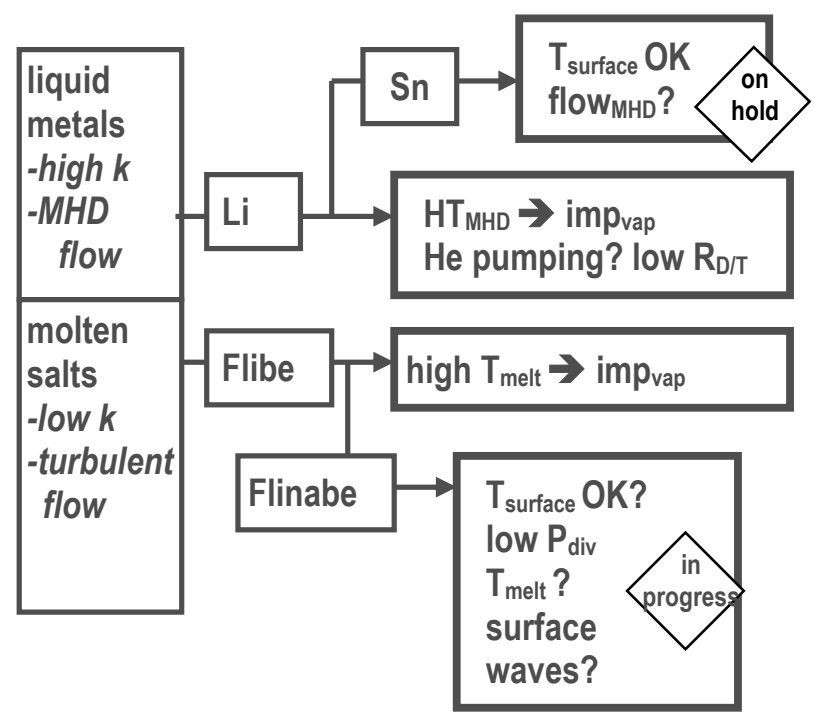

Figure 2. Summary of APEX research paths on liquid surface chamber designs 
Figures 1-12 for FED Special Issue Paper: Nygren et al., A Fusion Reactor Design with a Liquid First Wall and Divertor
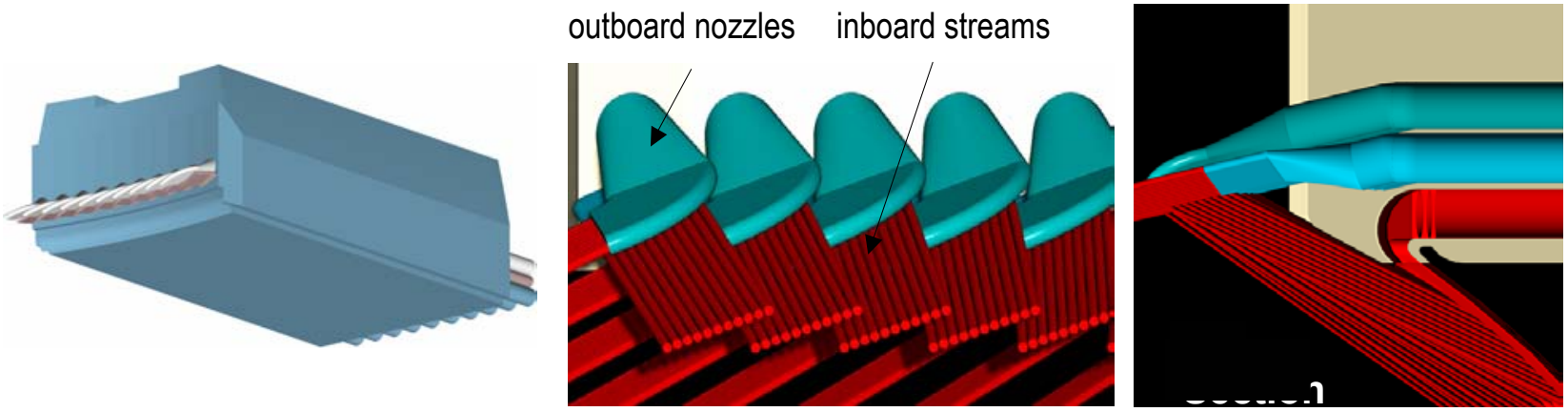

Figure 4. Self-shielding nozzles: module (left), front view of fast flow cassette nozzles (center), side cutaway view of flow cassette (right).

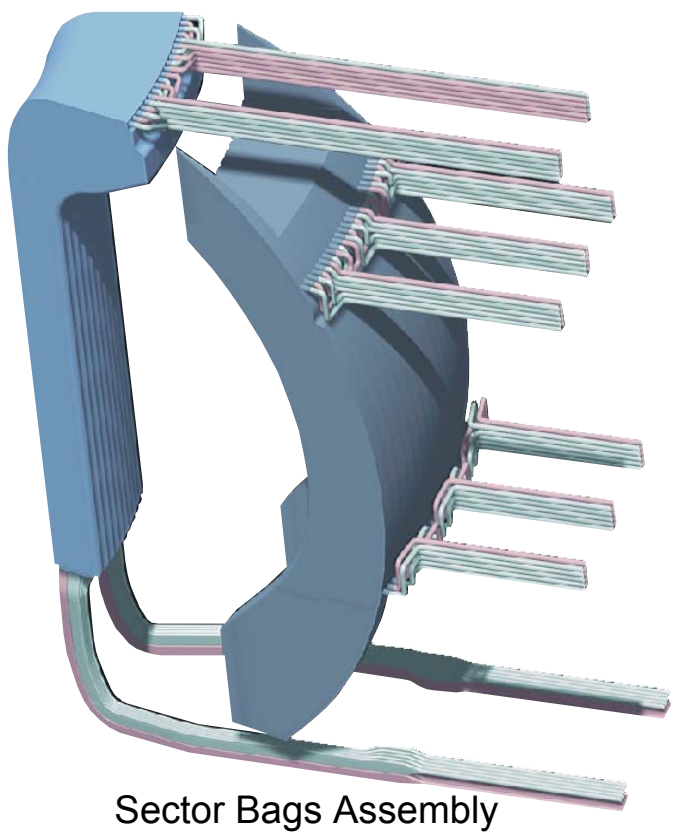

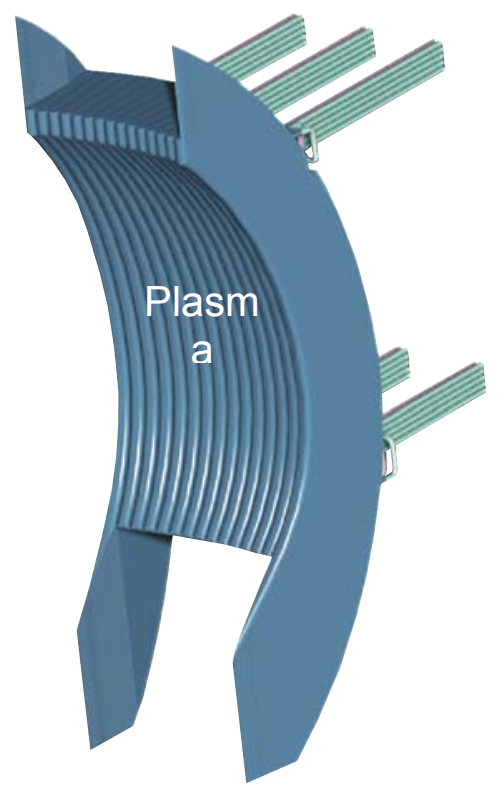

Outboard Bags

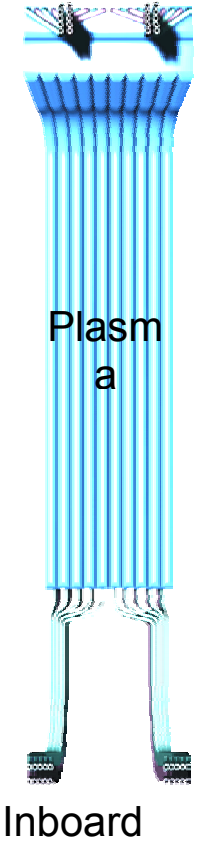

Figure 5. SiC bag to form blanket with flexible wall. 
Figures 1-12 for FED Special Issue Paper: Nygren et al., A Fusion Reactor Design with a Liquid First Wall and Divertor

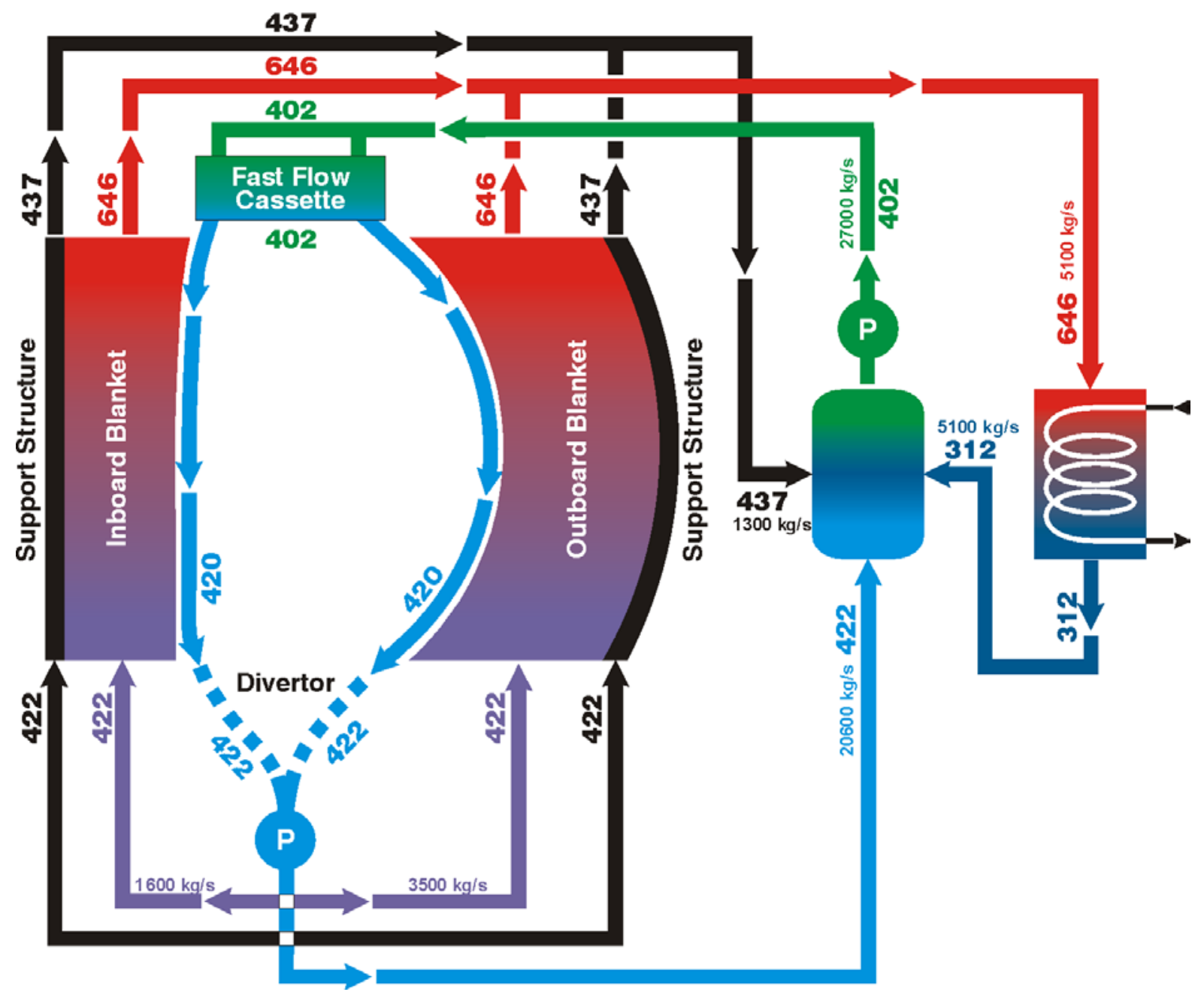

Figure 6. Diagram of Flinabe streams and temperatures.

Figure 7. Fast flow configuration for first wall and divertor.

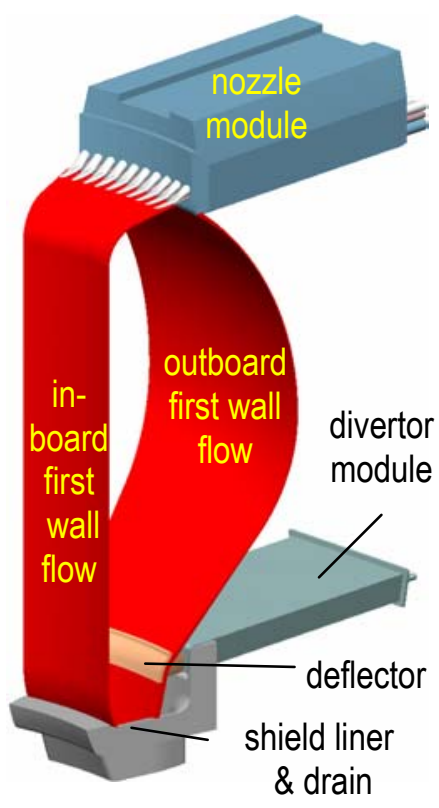


Figures 1-12 for FED Special Issue Paper: Nygren et al., A Fusion Reactor Design with a Liquid First Wall and Divertor
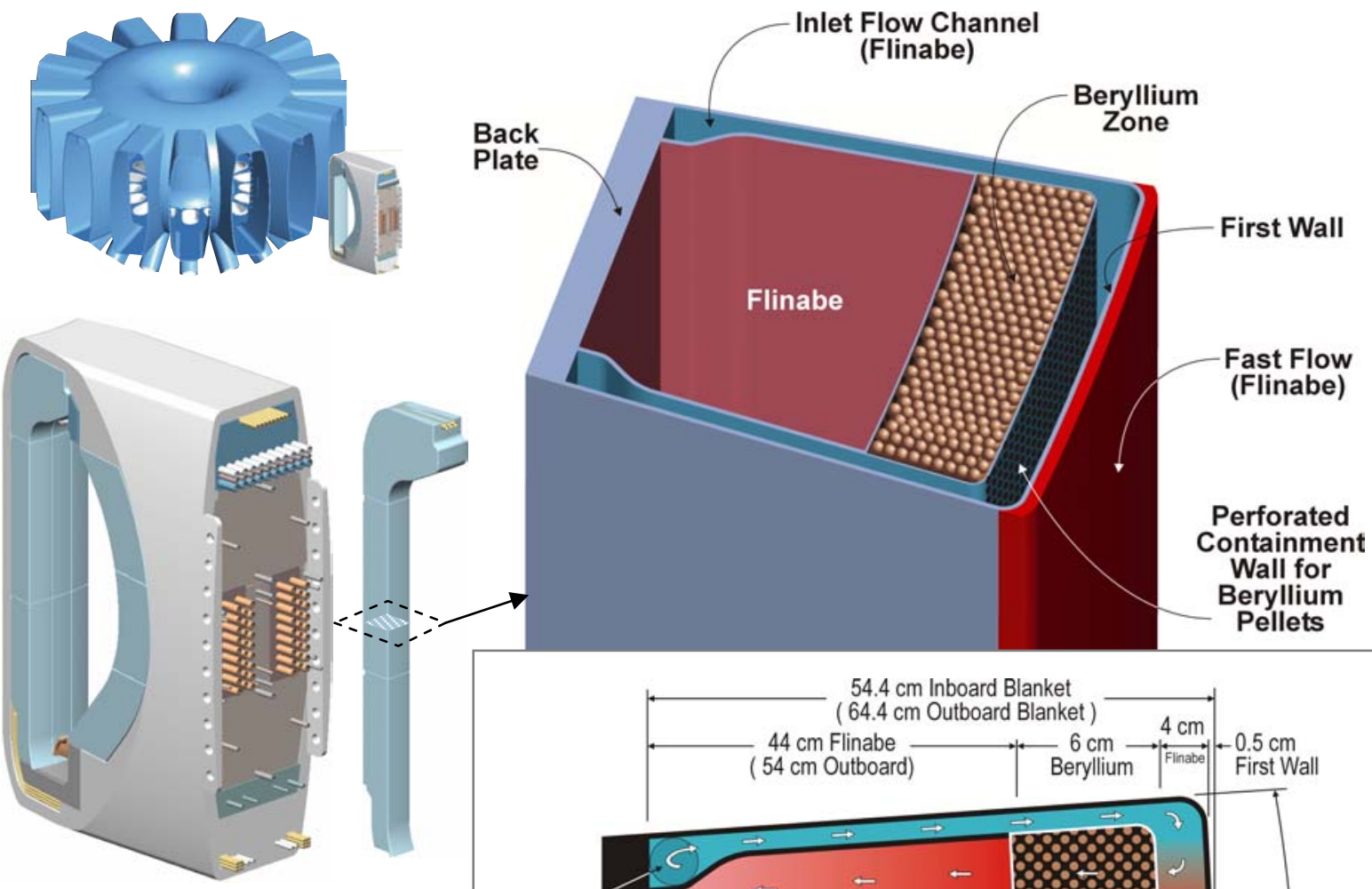

Figure 8. Blanket sector and cross-section of inboard blanket module. Inset (right) shows dimensions and distribution of Flinabe temperatures.

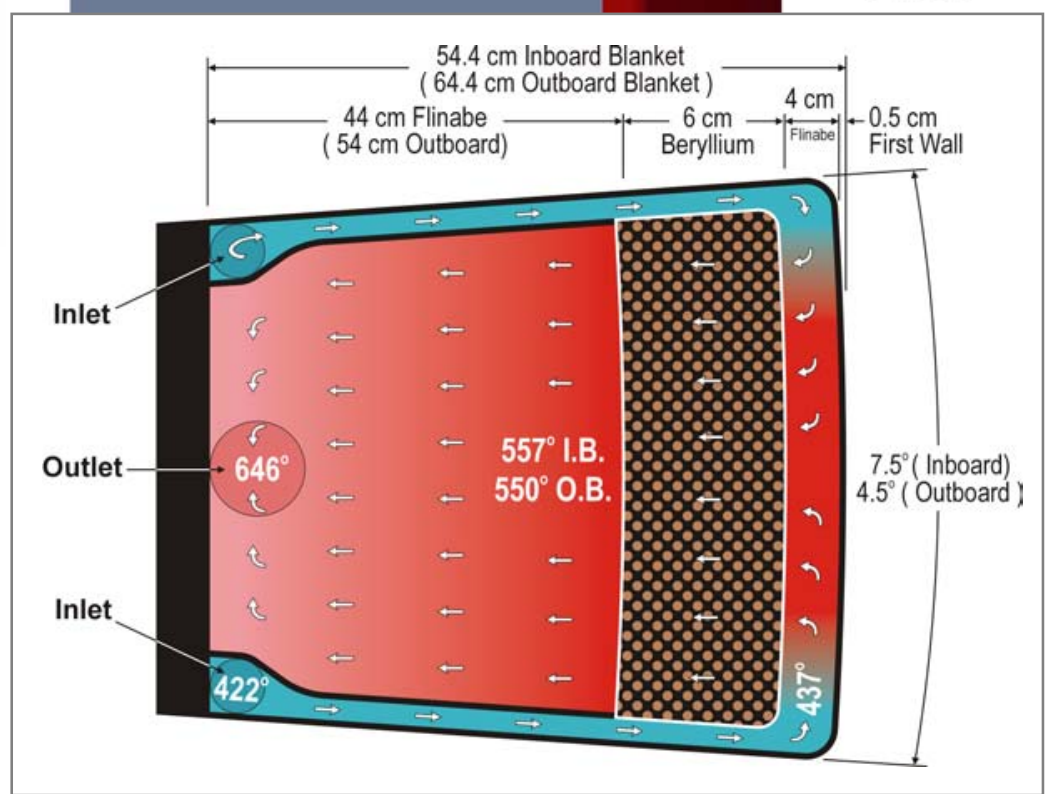


Figures 1-12 for FED Special Issue Paper: Nygren et al., A Fusion Reactor Design with a Liquid First Wall and Divertor

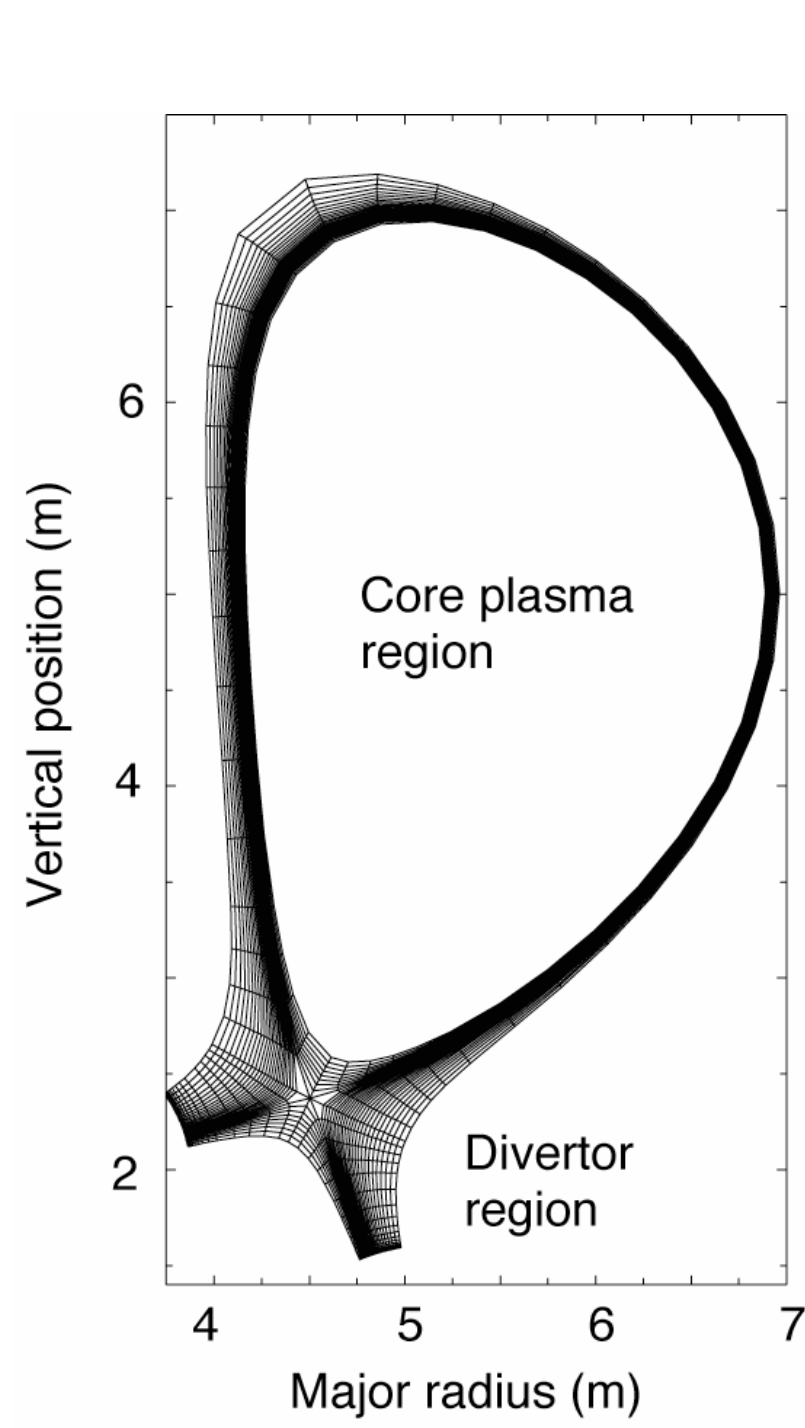

Figure 9. Mesh for UEDGE 2-D model of APEX/ARIES plasma edge.

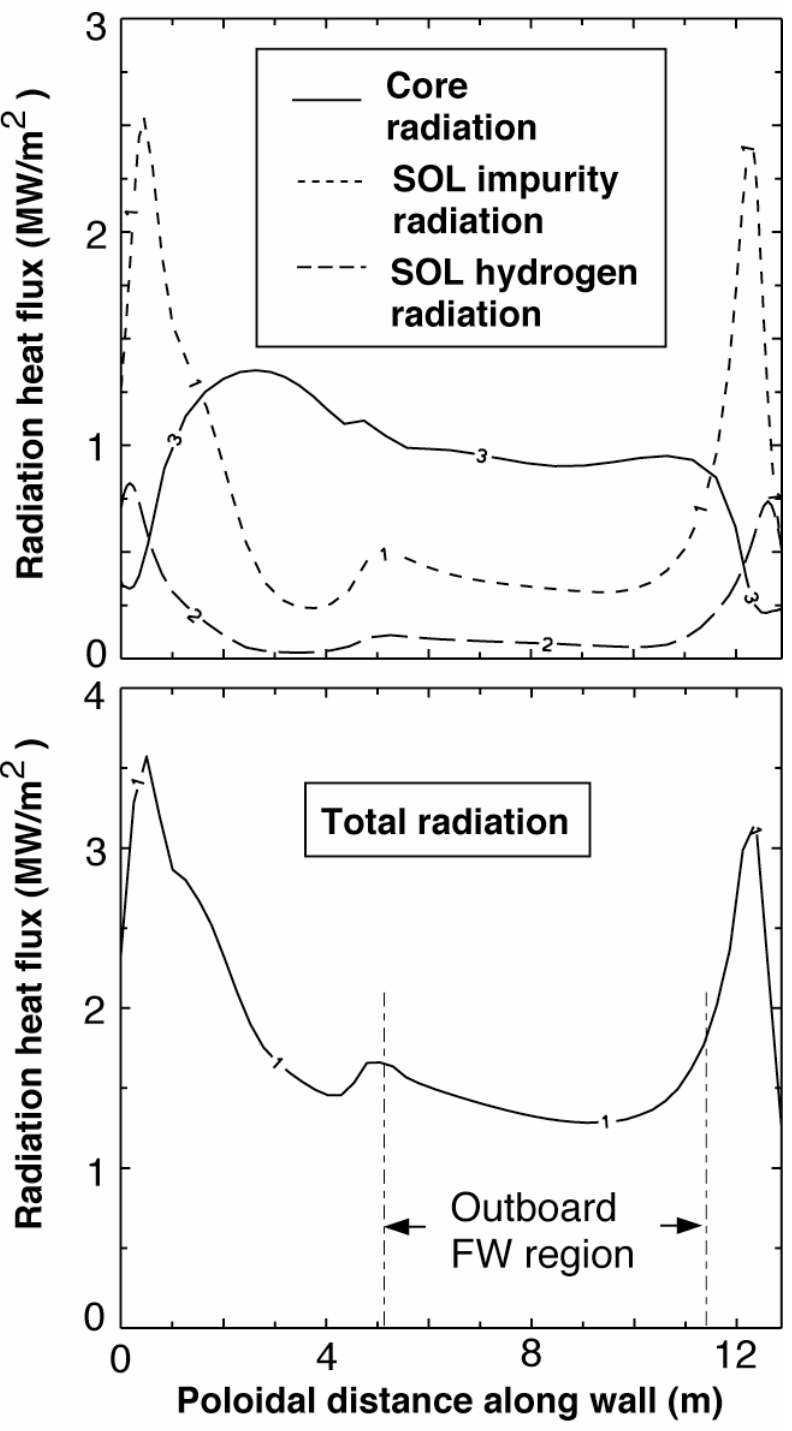

Figure 10. Radiated heat flux vs. distance around the chamber from UEDGE model. 
Figures 1-12 for FED Special Issue Paper: Nygren et al., A Fusion Reactor Design with a Liquid First Wall and Divertor
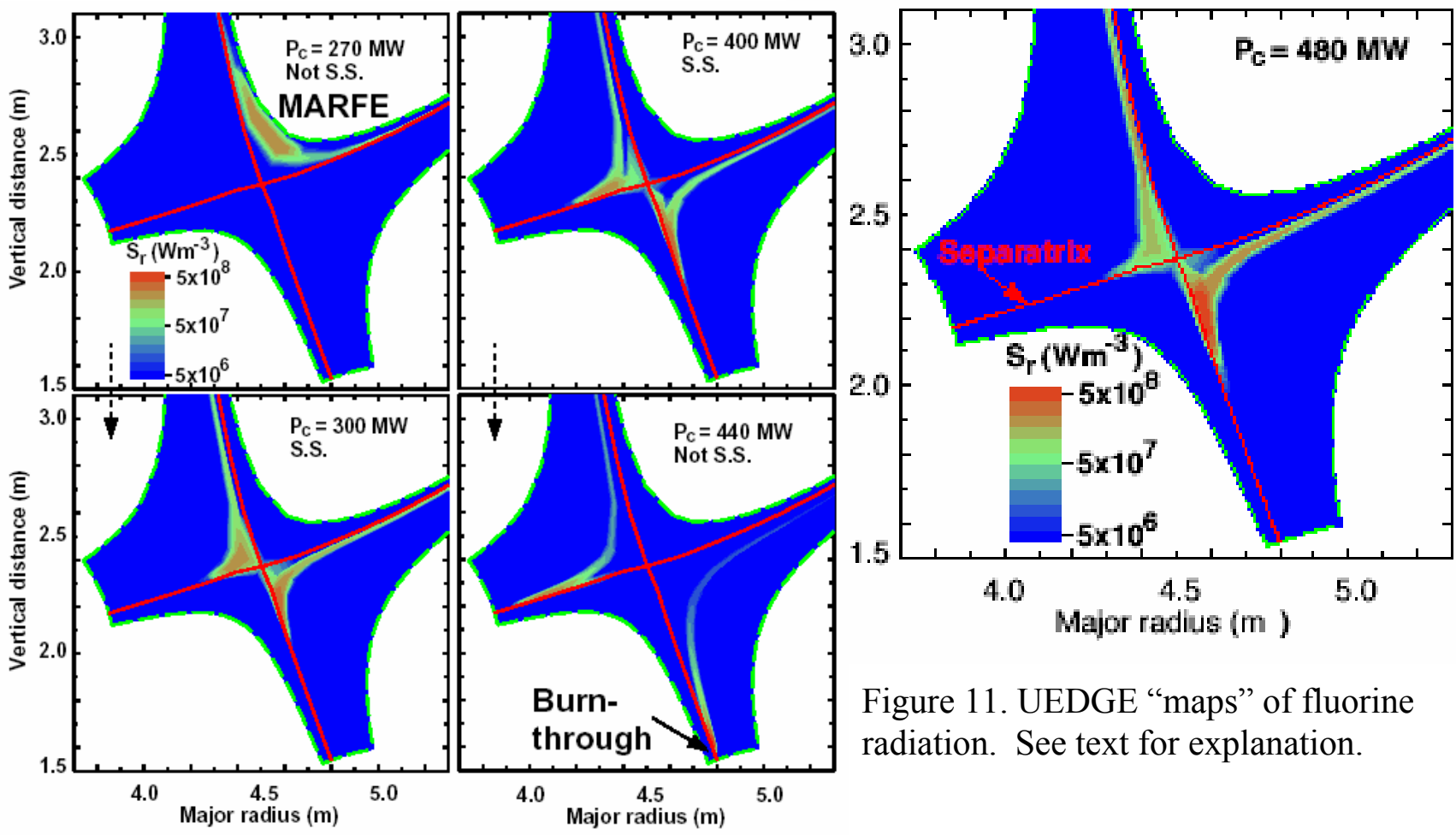

Figure 11. UEDGE "maps" of fluorine radiation. See text for explanation.

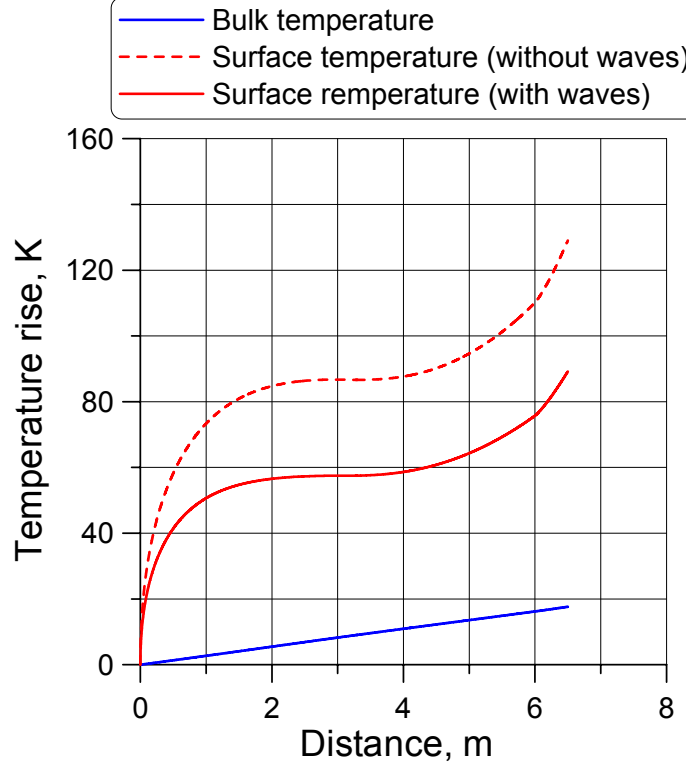

Figure 12. Temperature rise of Flinabe first wall vs. distance along flow path.

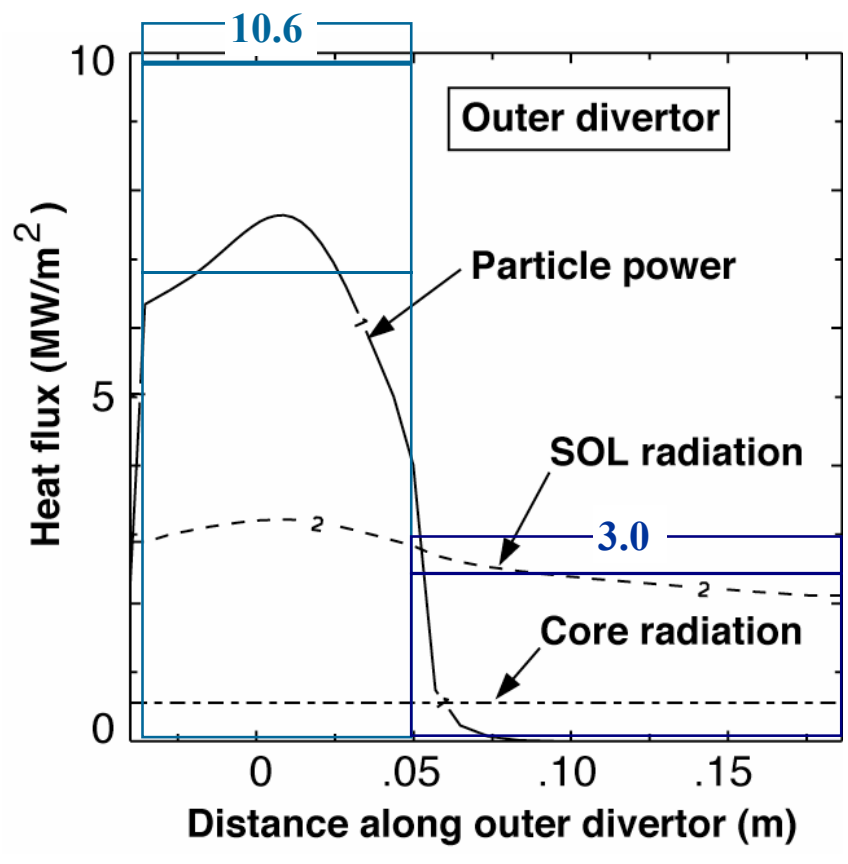

Figure 13. Heat load profiles for the divertor from UEDGE and average values for peak and background. 
Figures 1-12 for FED Special Issue Paper: Nygren et al., A Fusion Reactor Design with a Liquid First Wall and Divertor

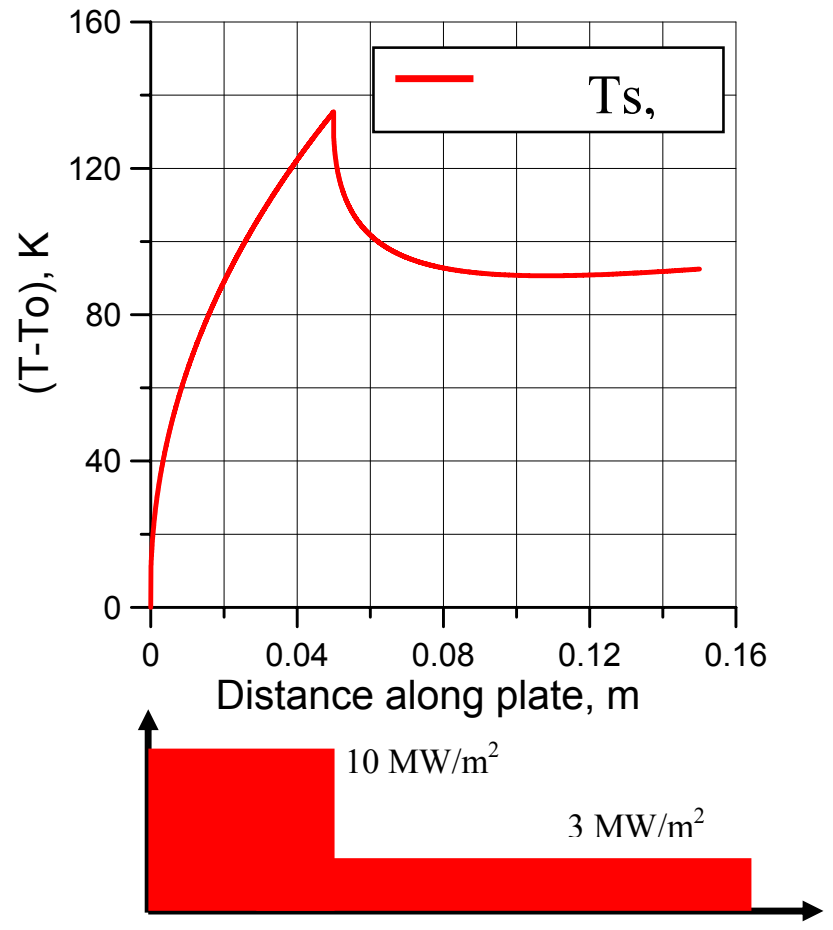

Figure 14. Temperature rise of Flinabe in divertor vs. distance along flow.
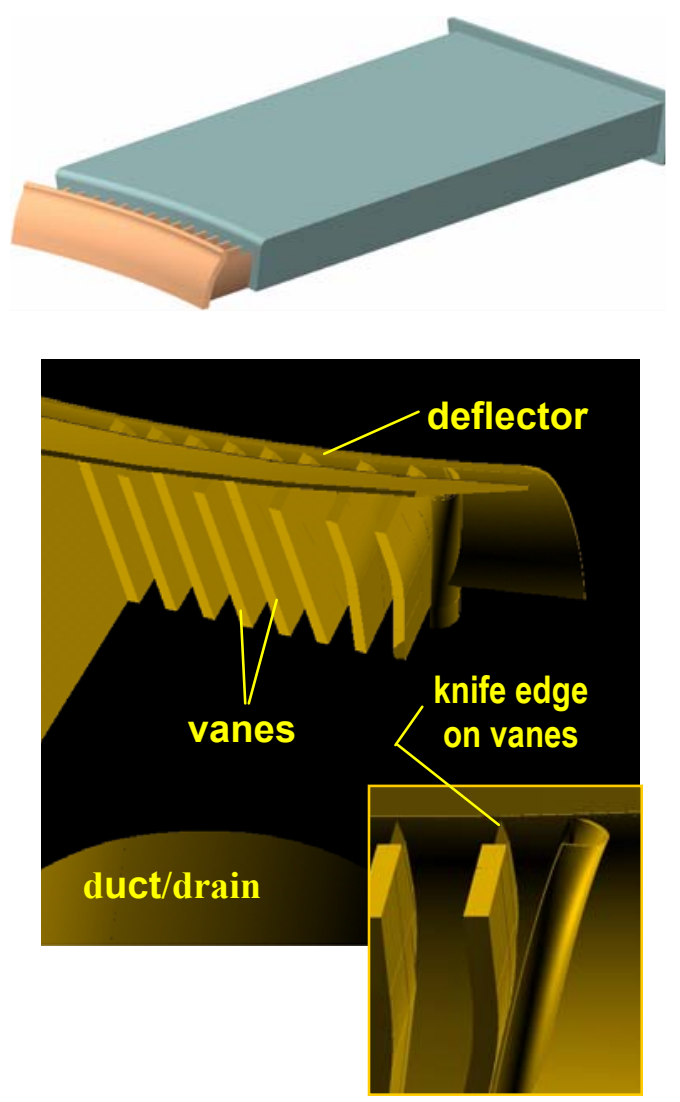

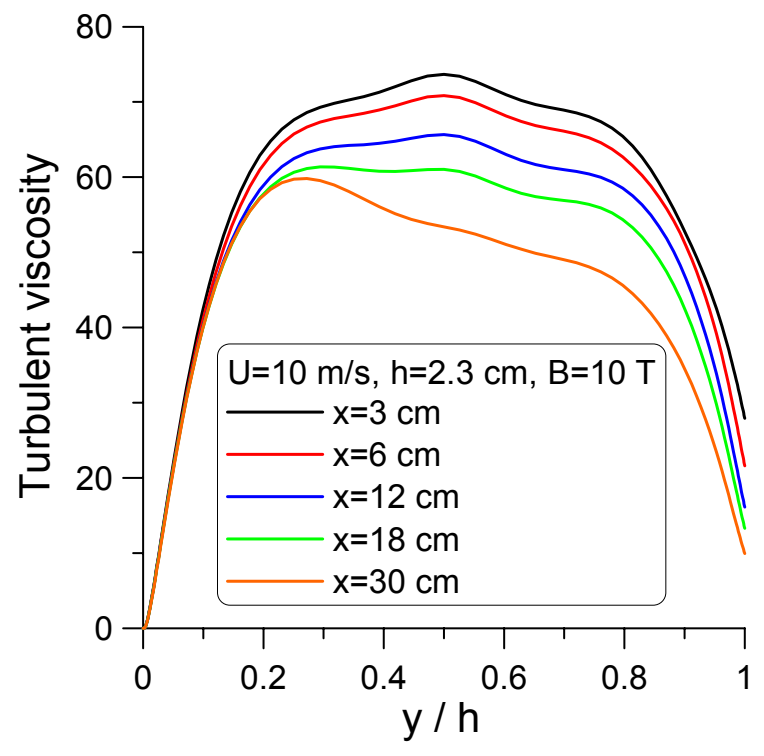

Figure 16. Profiles of turbulent viscosity vs. normalized distance from back surface of flow at several distances downstream from
Figure 15. CAD drawing of divertor cassette (top) and back-side view (PATRAN Model) of deflector (hottom). 
Figures 1-12 for FED Special Issue Paper: Nygren et al., A Fusion Reactor Design with a Liquid First Wall and Divertor

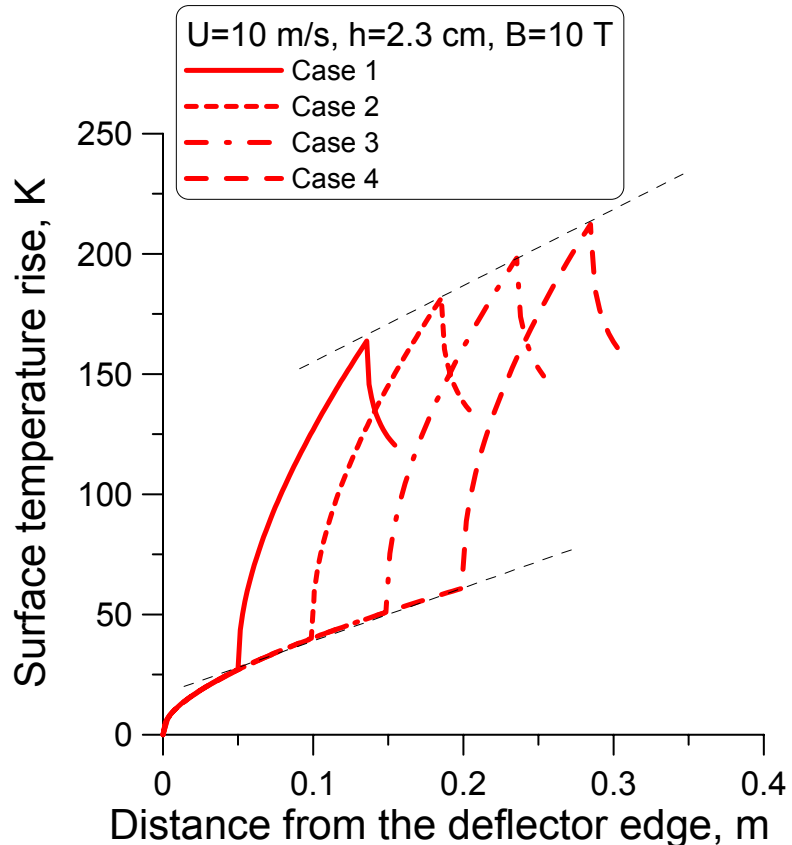

Figure 17. Surface temperature vs. distance from exit of deflector along divertor flow for four cases with the peak divertor heat flux located at 5, 10, 15 or $20 \mathrm{~cm}$ downstream from the deflector.
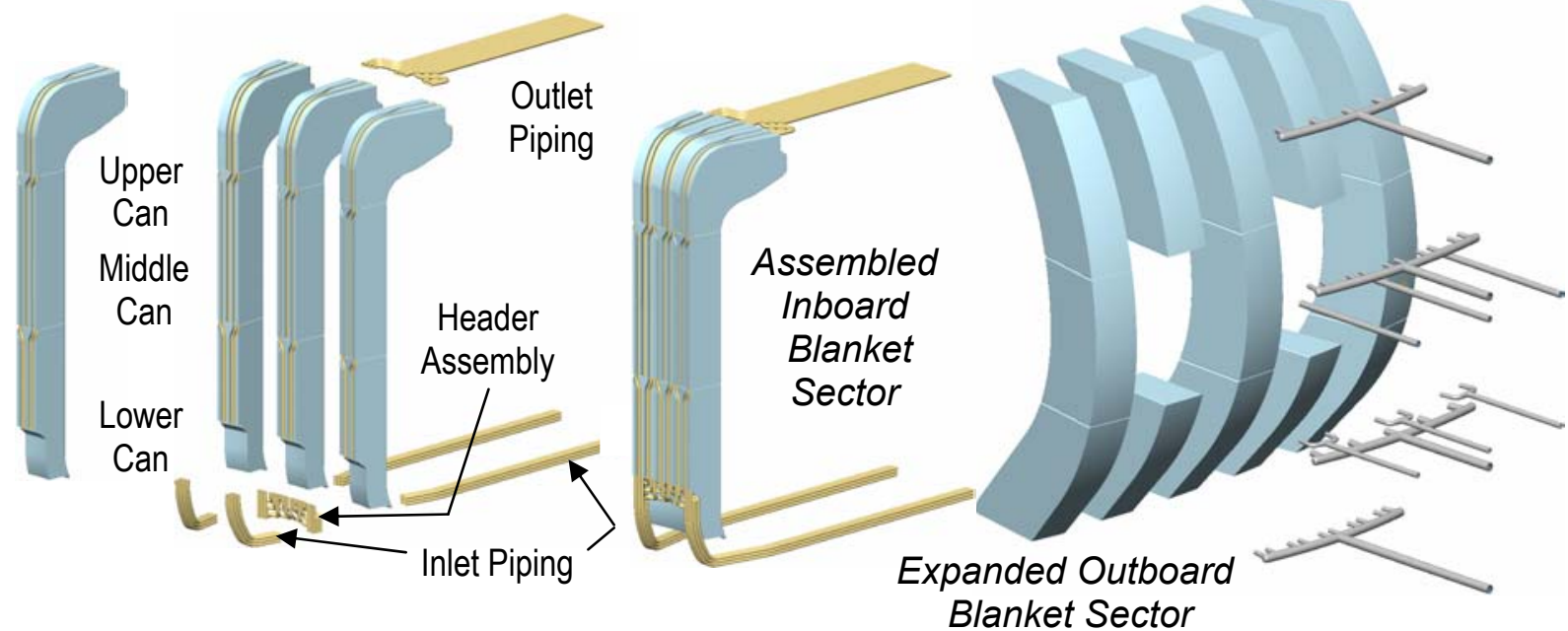

Figure 18. Modules and assembly for inboard blanket (left) and outboard blanket (right). 
Figures 1-12 for FED Special Issue Paper: Nygren et al., A Fusion Reactor Design with a Liquid First Wall and Divertor
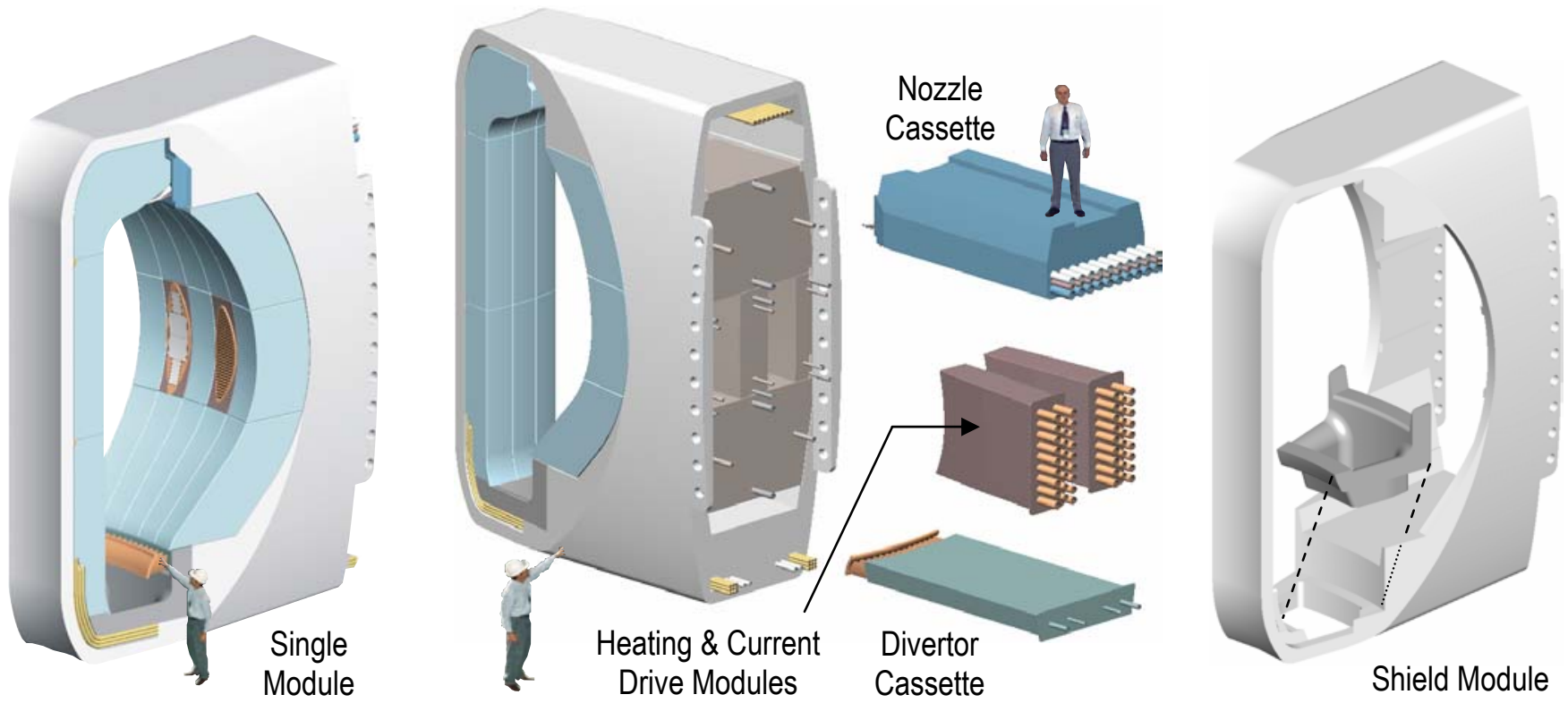

Figure 19. CAD drawings of nested modules and cassettes in place (left) and withdrawn (center) from the shield module (light gray) with blanket modules are still in place. Drawing on right shows removable shield liner (dark gray) above its location after installation.

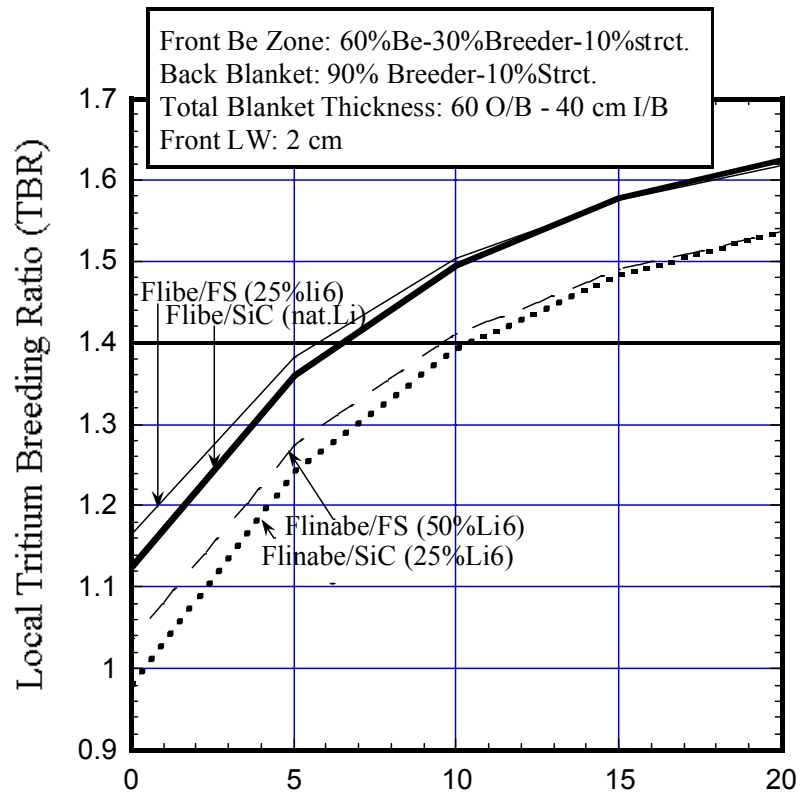

Front Beryllium Zone Thickness, cm

Figure 20. Enhancement of Tritium Breeding Ratio (TBR) with increasing the thickness of the Beryllium Multiplier Zone in the initial chamber design.

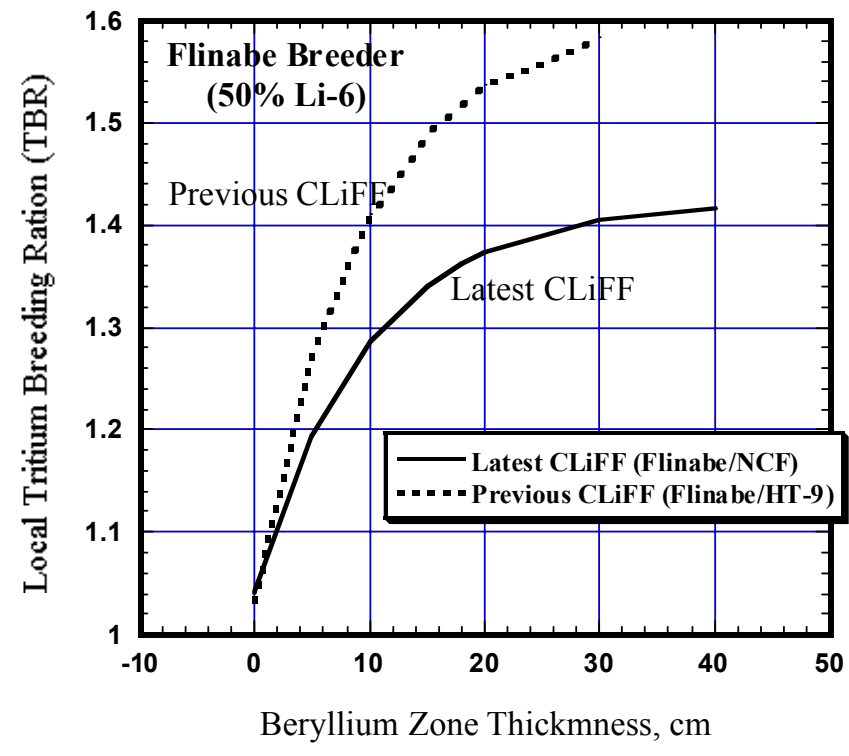

Figure 21. Comparison of the Local Tritium Breeding Ratio (TBR) between the initial and later configuration versus 
Figures 1-12 for FED Special Issue Paper: Nygren et al., A Fusion Reactor Design with a Liquid First Wall and Divertor

Attenuation Length of X-Rays Versus Photon Energy

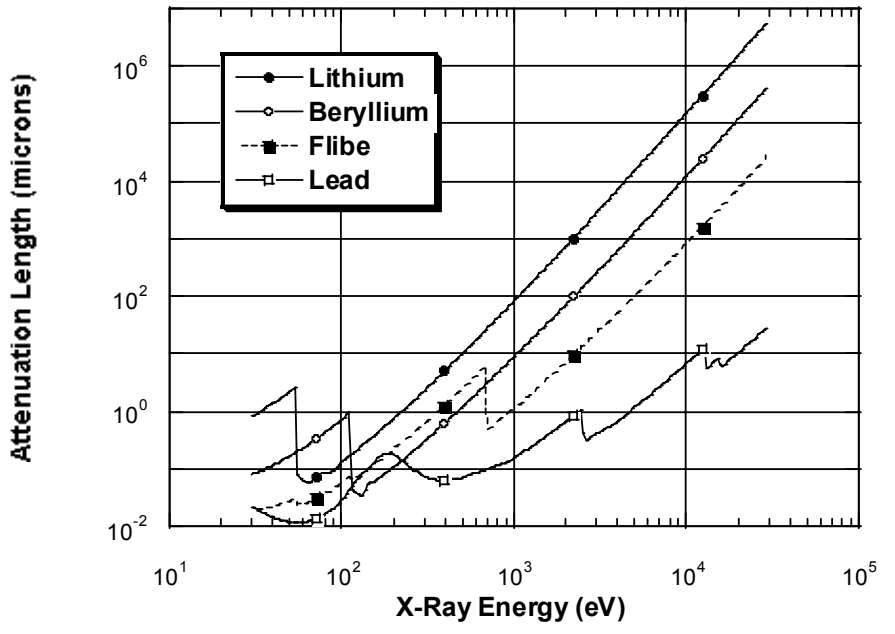

Figure 22. Attenuation Length (mean free path) of X-rays in several materials

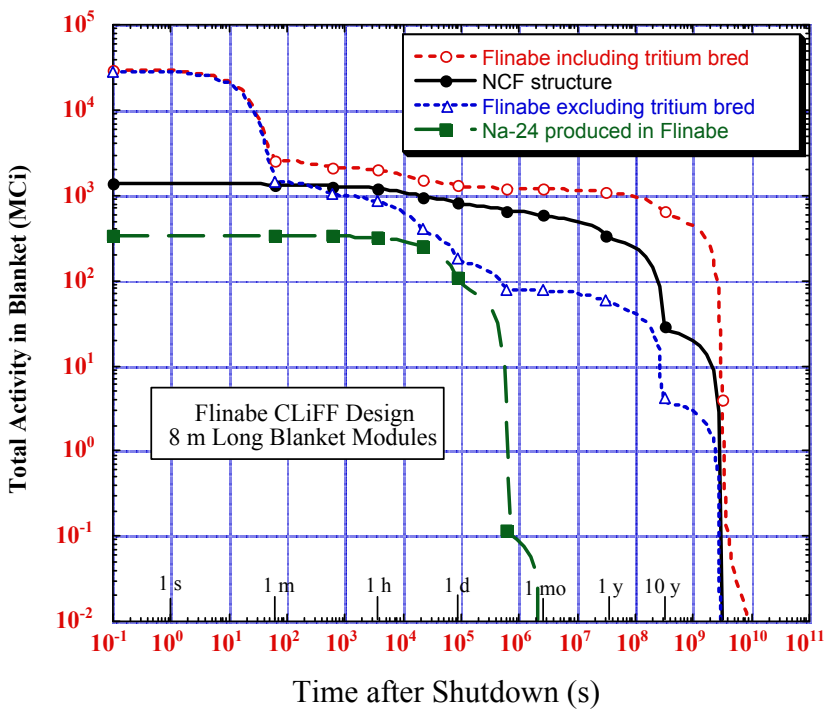

Figure 23. Total activity generated in the Flinabe blanket.

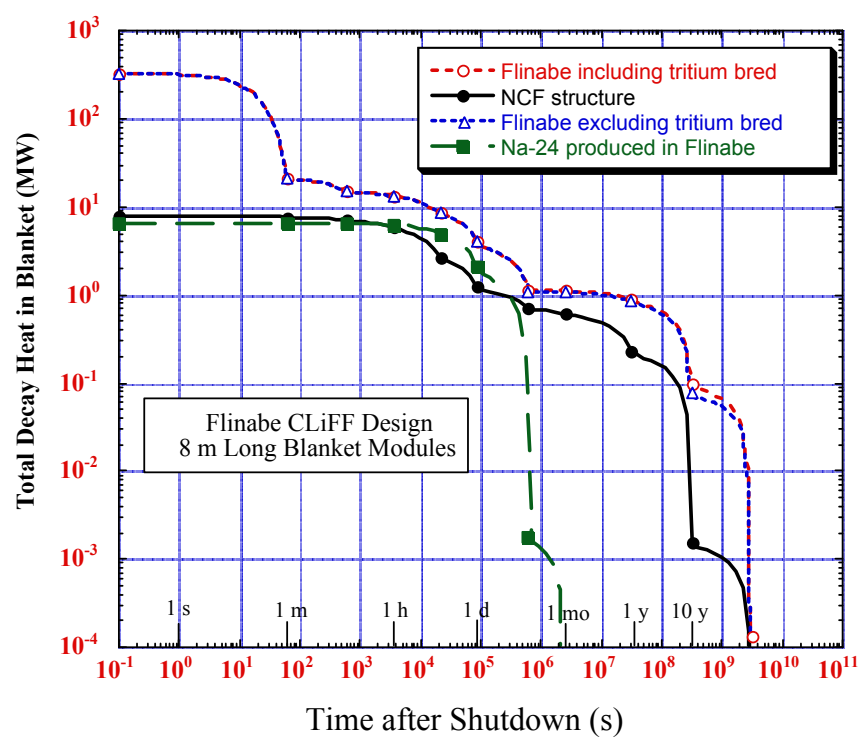

Figure 24. Total decay heat generated in the Flinabe blanket. 